\title{
La evaluación de impacto ambiental en las Islas Baleares: la normativa autonómica en el marco del régimen comunitario y estatal
}

\author{
Bartomeu Trias Prats \\ Profesor ayudante de Derecho Administrativo \\ Universitat de les Illes Balears
}

Sumario: I. ETAPA PRELIMINAR: LAS BASES ORGANIZATIVAS. LA CREACIÓN DE LA COMISIÓN BALEAR DE MEDIO AMBIENTE.-II. PRIMERA ETAPA: LA EVALUACIÓN DE PROYECTOS. LA PRIMERA NORMATIVA COMUNITARIA, ESTATAL Y AUTONÓMICA. 1. La Directiva 1985/337/CEE, de 27 de junio. 2. El Decreto 4/1986, de 23 de enero. 3. El Real Decreto Legislativo1302/1986. 4. El defectuoso encaje de la normativa autonómica en el marco comunitario y estatal.-III. SEGUNDA ETAPA: LA EVALUACIÓN DE PROYECTOS. LA MODIFICACIÓN DE LA NORMATIVA COMUNITARIA, ESTATAL Y AUTONÓMICA. 1. La Directiva 1997/11/CE, de 3 de marzo. 2. La revisión de la normativa básica estatal: el Real Decreto-ley 9/2000, de 6 de octubre, la Ley 6/2001, de 8 de mayo, y la Ley 62/2003, de 30 de diciembre, de medidas fiscales, administrativas y de orden social. 3 . La nueva modificación de la normativa comunitaria y estatal: la Directiva $2003 / 35 / C E$, de 26 de mayo, y las leyes estatales 9/2006, de 28 de abril, y 27/2006, de 18 de julio. 4. La revisión inexistente del régimen autonómico: el Decreto 85/2004, de 1 de octubre.-IV. TERCERA ETAPA: LA EVALUACIÓN ESTRATÉGICA DE PLANES Y PROGRAMAS. LA NORMATIVA COMUNITARIA Y ESTATAL. 1. La Directiva 2001/42/CE, de 27 de junio. 2. La Ley 9/2006, de 28 de abril.-V. ETAPA FINAL: LA NUEVA REGULACIÓN AUTONÓMICA DE LA EVALUACIÓN DE PROYECTOS Y PLANES. 1. La Ley 11/2006, de 14 de septiembre. Consideraciones generales. 2. La evaluación de proyectos. 3. La evaluación de planes y programas. 4. Especial referencia al régimen transitorio de la Ley 11/2006. 5. Reflexión final.

\section{ETAPA PRELIMINAR: LAS BASES ORGANIZATIVAS. LA CREACION DE LA COMISION BALEAR DE MEDIO AMBIENTE}

La primera norma sustantiva reguladora de los estudios de evaluación de impacto ambiental aparece en la Comunidad Autónoma de las Islas Baleares a principios del año 1986. No obstante, poco antes, a mediados del año 1985, el Decreto 38/1985, de 30 de mayo, será el que siente las bases efectivas para la futura implantación de los estudios de evaluación de impacto ambiental, con la creación de la denominada Comisión Balear de Medio Ambiente ${ }^{1}$.

\footnotetext{
${ }^{1}$ El Decreto 38/1985 ha sufrido numerosas modificaciones, referidas a los aspectos organizativos de la Comisión Balear de Medio Ambiente: Decreto 116/1985, de 28 de noviembre; Decreto 51/1988, de
} 
El artículo 1 de la citada norma reglamentaria atribuía a la Comisión Balear de Medio Ambiente la genérica responsabilidad de elaborar cuantas propuestas fueran procedentes al objeto de «la adopción y desarrollo de una política integrada de defensa, ordenación y mejora del medio ambiente en el ámbito territorial de las Islas Baleares». Más adelante, no obstante, el artículo 3 daba mayor concreción a las anteriores atribuciones mediante el establecimiento de una lista (abierta) de funciones específicas encomendadas a la Comisión, entre las cuales se señalaba expresamente la de «conocer los proyectos y planes que afecten de forma relevante al medio ambiente y emitir dictamen sobre los mismos». En la línea de ese propósito, más adelante aún, el artículo 6 del Decreto preveía la existencia, dentro de la estructura orgánica de la Comisión, del Comité de Evaluaciones de Impacto Ambiental, definido en el primer párrafo del artículo 17 como el comité especializado que «tiene una misión eminentemente técnica de aplicación y desarrollo de las diferentes metodologías existentes o posibles para evaluar cuantitativa o cualitativamente las consecuencias de las acciones o planes que incidan en el medio ambiente». Con mayor precisión, los párrafos siguientes de este último precepto citado asignaban al Comité de Evaluaciones de Impacto Ambiental la función de «elaborar la relación de planes, proyectos o acciones que, a su juicio, deban someterse a un estudio previo de evaluación de impacto ambiental, definiendo los posibles tipos de estudio según la importancia de la actuación de que se trate», así como también la de "proponer la metodología a seguir en la tramitación de la Evaluaciones de Impacto Ambiental».

Como ha quedado indicado, en el momento de aprobarse el Decreto 38/1985 no existía en la Comunidad Autónoma ninguna normativa general reguladora de los estudios de evaluación de impacto ambiental; ninguna normativa, pues, que determinase qué tipo de actuaciones eran, y de que forma, las que debían someterse al estudio previo de sus posibles repercusiones sobre el medio ambiente. Tal normativa, por otra parte, no existía tampoco a nivel estatal, ni siquiera a nivel comunitario ${ }^{2}$, aunque una y otra tardarían

12 de mayo; Decreto 114/1993, de 30 de septiembre; Decreto 96/1995, de 14 de septiembre; Decreto 151/1996, de 12 de julio; Decreto 43/1999, de 23 de abril; Decreto 212/1999, de 1 de octubre; Decreto 120/2003, de 11 de julio; y Decreto 30/2004, de 26 de marzo.

${ }^{2}$ No obstante, los estudios de evaluación de impacto ambiental constituían una técnica ya conocida en el derecho comparado, e incluso recogida en nuestro propio ordenamiento jurídico, si bien que de forma muy fragmentaria: como ejemplos relevantes pueden citarse la Ley 29/1985, de 2 de agosto, de Aguas; o, anteriores, el Reglamento de Actividades Molestas, Insalubres, Nocivas y Peligrosa, de 30 de noviembre de 1961, y la Orden del Ministerio de Industria de 18 de octubre de 1976, relativa a los proyectos de nuevas industrias potencialmente contaminadoras de la atmósfera. Sobre el origen de la evaluación de impacto ambiental y, en general, sobre su conceptuación y régimen pueden consultarse, entre la numerosa obra publicada, las siguientes monografías jurídicas: RosA MORENo, Régimen jurídico de la evaluación de impacto ambiental, Madrid, Trivium, 1993, 364 pp.; GARCía URETA, Marco jurídico del procedimiento de impacto ambiental: el contexto comunitario y estatal, Valencia, IVAP, 1994, 383 pp.; RAZQUín LIZÁrRaGa, Evaluación de impacto ambiental, Navarra, Aranzadi, 2000, 351 pp.; Quintana LóPeZ (Dir.), Comentario a la legislación de impacto ambiental, Madrid, Civitas, 2002, 488 pp. También pueden verse los capítulos específicos dedicados a la evaluación de impacto ambiental en 
escaso tiempo en aparecer. En este contexto, sin embargo, los preceptos mencionados del Decreto 38/1985 ponían claramente en evidencia el propósito de la Comunidad Autónoma de adoptar un mecanismo idóneo que permitiera introducir en los procesos de decisión administrativa la ponderación de las afecciones ambientales susceptibles de derivarse de tales decisiones. Faltaba aún por conocer qué concretas decisiones o actuaciones, y en qué términos o de qué modo, habían de verse sujetas a la evaluación de sus impactos ambientales; no obstante, la voluntad autonómica de avanzar en la línea del objetivo expuesto parecía decidida. Más aún, el texto del Decreto 38/1985 ofrecía un dibujo ciertamente amplio de la finalidad perseguida, pues las referencias reiteradas e indiscriminadas a «proyectos y planes» parecían dar a entender que la evaluación de impacto ambiental no se había de limitar a las decisiones técnicas (proyectos), sino que también había de hacerse extensiva a las de carácter estratégico (planes).

\section{PRIMERA ETAPA: LA EVALUACION DE PROYECTOS. LA PRIMERA NORMATIVA COMUNITARIA, ESTATAL Y AUTONOMICA}

\section{La Directiva $1985 / 337 / C E E$, de 27 de junio}

Apenas a un mes de crearse la Comisión Balear de Medio Ambiente fue aprobada la Directiva 1985/337/CEE del Consejo, de 27 de junio, sobre evaluación de las repercusiones de determinados proyectos públicos y privados sobre el medio ambiente. La norma, asentada sobre la convicción de que la autorización de los proyectos que pueden tener efectos significativos sobre el medio ambiente sólo debe hacerse efectiva después de una evaluación de tales repercusiones, respondía al propósito de armonizar la legislación de los estados miembros en la definición de los principios rectores de la evaluación de impacto ambiental; y, particularmente, en lo relativo a la determinación de los proyectos que debían someterse a evaluación, a las obligaciones que habían de imponerse a los promotores de los mismos y, por último, al contenido que debían reunir los estudios de evaluación de impacto ambiental.

En primer lugar, la Directiva (art. 1) imponía a los estados miembros la obligación de adoptar las disposiciones oportunas al efecto de garantizar que los proyectos que pudieran tener repercusiones importantes sobre el medio ambiente, debido en particular a su naturaleza, sus dimensiones o su locali-

tratados generales sobre Derecho Ambiental: LozAno CUTANDA, Derecho Ambiental Administrativo, Madrid, Dykinson, 2000, 386 pp.; Lozano CuTANDa y Alonso GaRcía, Diccionario de Derecho Ambiental, Madrid, Iustel, 2006, 1412 pp.; MARTín MATEO, Manual de Derecho Ambiental, Navarra, Aranzadi, 2003, 273 pp.; Martín MAteo, Tratado de Derecho Ambiental, Madrid, Trivium, 4 v.; OrtegA Álvarez (Dir.), Lecciones de Derecho del Medio Ambiente, Valladolid, Lex Nova, 2005, 616 pp. 
zación, fuesen sometidos, antes de la autorización, a una evaluación de sus repercusiones ambientales ${ }^{3}$.

En segundo lugar, la Directiva (art. 3) exigía que el estudio de las repercusiones ambientales de los proyectos permitiera identificar, describir y evaluar de forma adecuada los efectos directos e indirectos de los mismos sobre una pluralidad de factores diversos (el hombre, la fauna y la flora, el suelo, el agua,...). Por ello, el artículo 5.2 se preocupaba especialmente de detallar el contenido de la información que debía proporcionar el promotor del proyecto ${ }^{4}$.

En tercer lugar, por último, la Directiva (art. 2) imponía a los estados miembros la obligación de articular el oportuno procedimiento al objeto de hacer efectiva la evaluación de impacto ambiental, entendiendo que tal evaluación, bien podría integrarse en los propios procedimientos de autorización de los proyectos sometidos a evaluación, bien, en otro caso, en procedimientos específicos establecidos al efecto por los estados miembros. Fuera de uno u otro modo, no obstante, la Directiva imponía siempre la obligación de respetar en el procedimiento las exigencias sobre información y consultas establecidas en los artículos 6 y $7^{5}$; añadiendo, en los artículos 8 y 9 , que el

\footnotetext{
${ }^{3}$ La concreción de los proyectos que quedaban sometidos a la evaluación previa de sus impactos ambientales venia determinada por la relación del artículo 4 con los anexos I y II. Así, los proyectos incluidos en alguna de las clases enumeradas en el anexo I se consideraban necesariamente generadores de repercusiones notables sobre el medio ambiente, razón por la cual el art. 4.1 disponía la obligación en todo caso de someterlos a una evaluación sistemática de sus efectos. Por contra, los proyectos comprendidos en alguna de las clases recogidas en el anexo II no necesariamente habían de generar siempre aquellas repercusiones, de modo que el artículo 4.2 sólo imponía su sujeción a la evaluación de impacto ambiental cuando los estados miembros (las autoridades competentes designadas por éstos) así lo exigieran (bien mediante la identificación en lista de los tipos de proyectos que debían ser objeto de evaluación, bien mediante el establecimiento de criterios o umbrales determinantes, para los proyectos del anexo II, de la obligación de evaluar sus repercusiones ambientales). Finalmente, la delimitación del ámbito material de aplicación de la Directiva se completaba, por vía negativa, con el establecimiento de dos excepciones de distinto nivel en los artículos 1 y 2. La primera hacía referencia a los proyectos destinados a fines de defensa nacional y a los adoptados mediante un acto legislativo nacional específico: ambos quedaban excluidos de la aplicación de la Directiva. La segunda, por su parte, aludía a aquellos proyectos que, en casos o por razones excepcionales, debían quedar igualmente excluidos del procedimiento de evaluación de impacto ambiental previsto en la norma comunitaria (si bien que en relación a ellos la Directiva imponía a los estados miembros notables obligaciones de información, dirigida tanto a la Comisión como al público nacional, sobre las circunstancias del proyecto y las razones de la exención)
}

${ }^{4}$ Que había de comprender, como mínimo, la descripción del proyecto en cuanto a su emplazamiento, concepción y dimensiones; la identificación y evaluación de los efectos principales que pudieran derivarse sobre el medio ambiente; y la descripción de las medidas previstas para evitar y reducir los efectos negativos importantes y, si fuera posible, remediarlos. A ello se añadía, en el art. 5.1, la obligación de los estados miembros de adoptar las medidas necesarias para garantizar la aportación, por parte del promotor del proyecto, de las diferentes informaciones especificadas en el anexo III, en la medida que: «a) los Estados miembros consideren que dichas informaciones son apropiadas en una determinada fase del procedimiento de autorización y según las características específicas de un proyecto determinado o de un tipo de proyecto y de los elementos del medio ambiente que puedan ser afectados. b) los Estados miembros consideren que se puede razonablemente exigir a un maestro de obras que reúna los datos teniendo en cuenta, entre otras cosas, los conocimientos y métodos de evaluación existentes». En tales casos, las informaciones requeridas por el anexo III resultaban mucho más exigentes.

${ }^{5} \mathrm{El}$ artículo 6 hacía referencia a las informaciones y consultas internas, esto es, las dirigidas tanto a las autoridades como al público nacional. El artículo 7, por su parte, hacía referencia a la información 
resultado de tales informaciones y consultas debería tomarse necesariamente en consideración en el marco del procedimiento de autorización, y que, una vez finalizado éste, la decisión adoptada debería a la vez ponerse a disposición del público, con detalle de su contenido y de los motivos y consideraciones que la hubieran fundamentado.

Todos los anteriores requerimientos impuestos por la Directiva debían ser cumplimentados por los estados miembros en el plazo máximo de tres años contados desde su notificación, lo cual señalaba como fecha límite el día 3 de julio de $1988^{6}$. Correspondía dentro de este plazo, pues, adoptar las disposiciones de derecho interno que fueran precisas para hacer efectivas las prescripciones de la norma comunitaria, sin perjuicio en todo caso de la facultad de los estados miembros de establecer normas más severas o exigentes en lo relativo a la determinación del ámbito de aplicación y procedimiento a seguir en las evaluaciones de impacto ambiental. Todas estas disposiciones, finalmente, debían ser comunicadas por los estados miembros a la Comisión una vez adoptadas, incluyendo también la lista de proyectos o, en su caso, los criterios o umbrales determinantes de la sujeción a evaluación de impacto ambiental de los proyectos enumerados en el anexo II.

\section{El Decreto 4/1986, de 23 de enero}

A) El Decreto 4/1986, de 23 de enero, de implantación y regulación de los estudios de evaluación del impacto ambiental constituye la primera norma que, con carácter general, va a regular la materia en el ámbito de la Comunidad Autónoma. Se trata, mas aún, de la primera regulación autonómica aprobada ${ }^{7}$, anterior incluso a la entrada en vigor de la normativa básica

transfronteriza, disponiendo que «cuando un Estado miembro constatare que un proyecto puede tener repercusiones importantes sobre el medio ambiente de otro Estado miembro, o cuando un Estado miembro que pueda ser afectado considerablemente lo solicite, el Estado miembro en cuyo territorio se piensa realizar el proyecto transmitirá al otro Estado miembro las informaciones recogidas en virtud del artículo 5, al mismo tiempo que las pone a disposición de sus propios nacionales».

${ }^{6}$ La Directiva fue notificada a los estados miembros el día 3 de julio de 1985.

${ }^{7}$ La regulación de los estudios de impacto ambiental aparece posteriormente en las restantes comunidades autónomas, recogida en las siguientes disposiciones normativas:

- Cataluña: Decreto 114/1988, de 7 de abril, de Evaluación del Impacto Ambiental. Posteriormente se ha de citar la Ley 3/1998, de 27 de febrero, de Intervención Integral de la Administración Ambiental (el Reglamento general de desarrollo de esta Ley se aprueba por Decreto 116/1999, de 18 de junio), en el sentido que integra el trámite de evaluación de impacto ambiental dentro del procedimiento de autorización ambiental exigida para determinadas actividades.

- Comunidad Valenciana: Ley 2/1989, de 3 de marzo, de Impacto Ambiental. El Reglamento ejecutivo es aprobado por Decreto 162/1990, de 15 de octubre. Asimismo, se ha de tener en cuenta la Ley 2/2006, de 5 de mayo, de Prevención de la Contaminación y Calidad Ambiental, cuyos artículos 16 a 19 hacen referencia a la evaluación de impacto ambiental.

- Aragón: Decreto 118/1989, de 19 de diciembre, sobre Procedimiento de Impacto Ambiental, y Decreto 148/1990, de 9 de noviembre, por el que se regula el Procedimiento para la Declaración de 


\title{
estatal sobre evaluación de impacto ambiental. Se trata, por otra parte, de una norma nacida con vocación de interinidad, que se justifica por razón del
}

\begin{abstract}
Impacto Ambiental en la Comunidad Autónoma de Aragón. Ambos decretos fueros más tarde derogados por el Decreto 45/1994, de 4 de marzo, de Procedimiento de Evaluación de Impacto Ambiental. Finalmente, en fecha reciente se ha aprobado la Ley 7/2006, de 22 de junio, de Protección Ambiental de Aragón, que incorpora la denominada evaluación ambiental estratégica (de planes y programas). Esta disposición legal mantiene en vigor el Decreto anterior en tanto no se lleve a efecto el desarrollo reglamentario de la ley y en todo aquello que no resulte contradictorio con sus determinaciones.
\end{abstract}

- Canarias: Ley 11/1990, de 13 de julio, de Prevención del Impacto Ecológico, y Decreto 40/1994, de 8 de abril, sobre obligatoriedad del Estudio de Impacto Ecológico en los proyectos de obras de promoción pública.

- Galicia: Decreto 442/1990, de 13 de septiembre, de Evaluación de Impacto Ambiental, y Decreto 327/1991, de 4 de octubre, de Evaluación de Efectos Ambientales para Galicia. La posterior Ley 1/ 1995, de 2 de enero, de Protección Ambiental, no ha afectado a la vigencia de los anteriores decretos en tanto no se dicten las disposiciones reglamentarias que desarrollen la regulación legal relativa a las evaluaciones de impacto ambiental, evaluaciones de efectos ambientales y evaluaciones de incidencia ambiental.

- Comunidad de Madrid: Ley 10/1991, de 4 de abril, para la Protección del Medio Ambiente. Esta norma ha sido derogada por la Ley 2/2002, de 19 de junio, de Evaluación de Impacto Ambiental.

- Extremadura: Decreto 45/1991, de 16 de abril, de Medidas de Protección del Ecosistema. Este Decreto fue anulado por sentencia del Tribunal Superior de Justicia de Extremadura 16/1993, de 28 de enero, en base a argumentos de orden competencial. No obstante, el posterior Decreto 25/1993, de 24 de febrero, convalidó aquél, asumiendo íntegramente el texto de la norma reglamentaria anulada.

- Cantabria: Decreto 50/1991, de 29 de abril, de Evaluación de Impacto Ambiental. La Ley 5/2002, de 4 de julio, se dicta posteriormente para dar rango legal a la exigencia de someter a un instrumento de evaluación ambiental los diferentes planes de ordenación territorial o urbanística que establezcan el marco para la autorización de cualquiera de los proyectos enumerados en los anexos I y II del Decreto 50/1991. En definitiva, la Ley 5/2002 se dicta para cubrir el vacio normativo que había provocado la anulación, por insuficiencia de rango, de varios preceptos del Decreto 50/1991, según lo establecido en la sentencia del Tribunal Superior de Justicia de Cantabria de 4 de marzo de 2002. La reciente Ley 17/2006, de 11 de diciembre, de Control Ambiental Integrado, ha venido a solventar definitivamente la cuestión, estableciendo con rango legal la regulación de las diferentes modalidades de estudios de impacto ambiental y, en consecuencia, derogando tanto el Decreto $50 / 1991$ como el artículo 2 y disposiciones transitorias 1 y 2 de la Ley 5/2002.

- Andalucía: Ley 7/1994, de 18 de mayo, de Protección Ambiental. En desarrollo de la Ley y para la regulación de los tres instrumentos de prevención ambiental que regula ésta se dictan posteriormente el Decreto 292/1995, de 12 de diciembre, que aprueba el Reglamento de Evaluación de Impacto Ambiental; el Decreto 297/1995, de 19 de diciembre, que aprueba el Reglamento de Calificación Ambiental; y el Decreto 153/1996, de 30 de abril, que aprueba el Reglamento de Informe Ambiental.

- Castilla y León: Ley 8/1994, de 24 de junio, que establece el marco legislativo en materia de Evaluaciones de Impacto Ambiental y Auditorias Ambientales. El Decreto 209/1995, de 5 de octubre, aprueba el Reglamento ejecutivo de la Ley. Posteriormente, el Decreto 129/1999, 17 de junio, aprueba el Reglamento de Auditorias Ambientales. No obstante, el Decreto Legislativo 1/2000, de 18 de mayo, que aprueba el Texto Refundido de la Ley de Evaluación de Impacto Ambiental y Auditorias Ambientales, deroga la Ley 8/1994; y, más tarde aún, la Ley 11/2003, de 8 de abril, de 2003, deroga buena parte del anterior Texto Refundido, dejando vigentes las disposiciones del Decreto 209/1995 en lo que no sean contradictorias con la nueva ley y no se produzca el desarrollo reglamentario de la misma.

- Murcia: Ley 1/1995, de 8 de marzo, de Protección del Medio Ambiente.

- País Vasco: Ley 3/1998, de 27 de febrero, General de Protección del Medio Ambiente.

- Castilla-La Mancha: Ley 5/1999, de 8 de abril, de Evaluación de Impacto Ambiental. El Decreto 118/2000, de 20 de junio, establece los umbrales y criterios determinantes de la sujeción al proce- 
momento de su aparición: ausente la normativa básica estatal y aún lejos la fecha que marcaba la finalización del plazo de transposición de la Directiva 1985/337/CEE. En este contexto, el Decreto 4/1986 lo que hace, pues, es aprobar unas denominadas «Normas Provisionales para el Estudio de Evaluaciones de Impacto Ambiental», recogidas en el anexo I de la propia norma reglamentaria ${ }^{8}$.

De la conjunción de las escasas disposiciones contenidas en el Decreto y de las «normas provisionales» recogidas en el citado anexo I resulta, en definitiva, la definición del régimen autonómico aplicable a las evaluaciones de impacto ambiental, del cual se pueden destacar los siguientes aspectos más significativos.

El ámbito de aplicación del Decreto queda limitado, desde el punto de vista subjetivo, a la administración autonómica, pues la norma reduce las actuaciones sometidas a previo estudio de impacto ambiental a aquellas que hayan de promover, autorizar o subvencionar «las consellerias y organismos de esta Comunidad Autónoma» (art. 3). Quedan excluidas de la evaluación, por tanto, la totalidad de actuaciones cuya promoción o autorización corresponda a alguno de los diferentes entes que integran la Administración Local ${ }^{9}$.

En la vertiente objetiva, por su parte, la aplicación del Decreto y del procedimiento de evaluación que éste regula queda en principio circunscrito a las diferentes actuaciones relacionadas en los anexos II y III de la norma (art. 2). Sin embargo, el Decreto (art. 3) prescribe que se podrá «exigir asi-

dimiento de evaluación de impacto ambiental de las actividades recogidas en el Anexo II. Sin embargo, la reciente Ley 4/2007, de 8 de marzo, de Evaluación Ambiental en Castilla-La Mancha, ha derogado expresamente la Ley 5/1999, debiéndose entender también derogadas todas las previsiones contenidas en el Decreto de 2000 que resulten contradictorias con la nueva regulación legal.

- La Rioja: Ley 5/2002, de 8 de octubre, de Protección del Medio Ambiente. Navarra: Ley foral 4/ 2005, de 22 de marzo de Intervención para la Protección Ambiental.

- Principado de Asturias: No cuenta con una normativa general reguladora de los estudios de impacto ambiental dictada en desarrollo de la legislación básica estatal. Sin embargo cabe mencionar, aún con carácter especial, los denominados «estudios previos de impacto ambiental», cuyo régimen aparece definido en la Ley 5/1991, de 15 de abril, de Espacios Naturales Protegidos, y desarrollado en el Decreto 11/1991, de 24 de enero, de aprobación de las Directrices Regionales de Ordenación, y Decreto 38/19994, de 19 de mayo, de aprobación del Plan de Ordenación de los Recursos Naturales de Asturias.

${ }^{8}$ Es del todo expresiva, en este sentido, la exposición de motivos del Decreto 4/1986. Después de dar cuenta del plazo de transposición de la directiva comunitaria, se dice: «este plazo de implantación, unido al hecho de no haberse aprobado aún en el Estado español la anunciada Ley General del Medio Ambiente, permite y aconseja la promulgación de una normativa provisional y progresiva, inicialmente para los órganos del Gobierno Balear, que deje un periodo de experimentación y corrección previo a la reglamentación definitiva y anterior a la elaboración de las disposiciones legales que regulen en la materia la actuación de otras administraciones».

\footnotetext{
${ }^{9}$ No obstante, también debe entenderse aplicable el Decreto en el caso de actuaciones comprendidas en él que se promuevan o hayan de autorizarse por los Consejos Insulares, siempre que se trate, entonces, de actuaciones relacionadas con materias cuya competencia ejecutiva haya sido transferida por la Comunidad Autónoma a los Consejos Insulares de acuerdo con los previsto en el artículo 39 del Estatuto de Autonomía.
} 
mismo la evaluación de aquellas actuaciones que, promovidas por la Administración autonómica, no figuren en dichos anexos pero que, presumiblemente, puedan tener una fuerte incidencia ambiental». De este modo, el Decreto (norma provisional 3) acaba distinguiendo, por razón de su función y contenido, hasta cuatro tipos diferenciados de estudios de impacto ambiental:

i) La evaluación de impacto ambiental detallada: es la que corresponde a las actuaciones que pueden tener o tienen gran incidencia en el medio ambiente y que la Administración califique como tales ${ }^{10}$. En concreto, la relación de las actuaciones que han de ser sometidas a evaluación detallada aparece recogida en el anexo II de la norma autonómica.

ii) La evaluación de impacto ambiental simplificada: es la que se refiere a las actuaciones que la Administración califique como de incidencia media ${ }^{11}$. El anexo III del Decreto es el que contiene la enumeración de las actuaciones que han de quedar sometidas a esta modalidad de estudio de impacto ambiental.

iii) La evaluación de impacto ambiental preliminar: definida como un avance de evaluación que permita una primera identificación y valoración de los impactos $\mathrm{y}$, en consecuencia, sirva para el posterior desarrollo del estudio de impacto ambiental en alguna de las dos modalidades anteriormente señaladas.

iv) El informe medioambiental: se trata de un estudio ambiental elemental para aquellas actuaciones que no deban ser sometidas a evaluación definitiva, esto es, detallada o simplificada. De hecho, la norma provisional 7 llega incluso a afirmar que los informes medioambientales «no son realmente evaluaciones de impacto ambiental, por cuanto se limitan a un informe que el autor de un plan o proyecto elabora, en forma de anexo del mismo, en el que se señalan las consideraciones ambientales tenidas en cuenta y las medidas correctoras adoptadas en dicho plan o proyecto».

Por último, en lo que se refiere al aspecto adjetivo, el Decreto establece el cumplimiento de los siguientes trámites en el procedimiento de evaluación de impacto ambiental, distinguiendo según se trate de actuaciones promovi-

\footnotetext{
${ }^{10} \mathrm{Al}$ tratarse de las actuaciones que pueden tener mayores repercusiones sobre el medio ambiente el Decreto (art. 4) impone a esta categoría de evaluaciones de impacto ambiental un elevado grado de profundización, que se traduce en la exigencia de unos contenidos mimos perfectamente equiparables a los que aparecían requeridos entonces por la Directiva 1985/337/CEE.

${ }^{11}$ En concordancia con la menor incidencia ambiental de las actuaciones sometidas a esta clase de evaluación el nivel de profundización exigido por el Decreto también es menor. La norma provisional 4 expresamente señala, en este sentido, que «su contenido es esencialmente el mismo que el de las evaluaciones de impacto ambiental detalladas, pero con un grado de profundización menor», lo que a la postre se traduce en una rebaja de las exigencias.
} 
LA EVALUACIÓN DE IMPACTO AMBIENTAL EN LAS ISLAS BALEARES: LA NORMATIVA...

das por la administración autonómica o de actuaciones que, promovidas por terceras personas, han de ser autorizadas por ésta ${ }^{12}$.

i) En el primer supuesto, el estudio de impacto ambiental deberá iniciarse, salvo casos justificados, con una evaluación preliminar, que se someterá a informe del Comité de Evaluaciones de Impacto Ambiental. Si la evaluación preliminar demostrara la inexistencia de impactos negativos relevantes, entonces el Comité podrá proponer la autorización de la actuación; en caso contrario, propondrá la continuación del estudio, señalando si la evaluación debe ser detallada o simplificada. Redactada en su caso una u otra, el documento de síntesis será objeto de informe por parte de los organismos interesados y se someterá asimismo a información pública (en el mismo trámite que la actuación de referencia o, si ésta no lo requiriera, en trámite individualizado $^{13}$ ). Por último, la evaluación de impacto ambiental, junto con el resultado de la información pública e informes, será remitida al Comité de Evaluaciones de Impacto Ambiental, al efecto de la emisión del informe final o «dictamen de impacto ambiental». Dicho dictamen será posteriormente presentado a la Comisión Permanente de la Comisión Balear de Medio Ambiente, para que ésta, con sus propias observaciones, lo eleve al departamento promotor que ha de tomar la decisión sobre la actuación proyectada.

ii) En el segundo supuesto, el procedimiento que prescribe el Decreto es sustancialmente idéntico al que se acaba de ver. Así, el promotor de la actuación que deba ser autorizada por la administración autonómica deberá presentar ante el departamento que haya de autorizarla una evaluación preliminar; y, a partir de aquí, el Decreto se remite directamente al cumplimiento de los restantes trámites señalados para el supuesto anterior.

B) Visto el contenido del Decreto autonómico 4/1986, saltan a la luz una serie de comentarios de los que conviene dejar constancia en este momento, que pueden plantearse desde dos ópticas diferentes.

Por una lado, cabría enfocar el Decreto desde una perspectiva interna. Desde aquí, es fácil advertir que se trata de una norma ciertamente comple$\mathrm{ja}$, que diseña en aspectos relevantes un régimen jurídico un tanto enmara-

\footnotetext{
${ }^{12}$ Los plazos previstos para el procedimiento han sido objeto, con frecuencia, de ampliaciones puntuales, con el propósito de permitir la resolución expresa de los expedientes iniciados en los casos de notable acumulación de los mismos. Cabe señalar, en este sentido, la Orden de Presidencia del Gobierno de 10 de septiembre de 1999 y las resoluciones del Consejero de Medio Ambiente de 14 de julio de 2003, 24 de noviembre de 2003, 31 de abril de 2004, 14 de julio de 2004 y 14 de mayo de 2006.

${ }_{13}$ Como excepción a la exigencia de información pública, el Decreto (norma provisional 8) prevé la posibilidad de omitir el trámite «en los casos en que la metodología utilizada (para la elaboración de la evaluación de impacto ambiental) haya previsto suficientes sistemas de compulsa y participación ciudadana a juicio del Comité de Evaluaciones de Impacto Ambiental»
} 
ñado, con algunas zonas oscuras; especialmente ocurre así en lo que se refiere a la determinación de las actuaciones que hayan de quedar sometidas a evaluación. En efecto, según dispone el artículo 2 del Decreto, en los anexos II y III se relacionan las actuaciones que deben ser objeto de evaluación de impacto ambiental en una de las dos modalidades a que hacen referencia los citados anexos: evaluación detallada (anexo II) y evaluación simplificada (anexo III). Sin embargo, cundo la norma regula el procedimiento de evaluación, exige entonces (norma provisional 8) que ésta empiece siempre («salvo casos justificados») con una evaluación preliminar, que será justamente la que sirva para determinar si la actuación puede ser autorizada sin mas trámites o, por el contrario, debe continuar el estudio de impacto ambiental en la versión detallada o simplificada. Surge así un interrogante evidente: ¿cuáles son las actuaciones que se han de someter a la evaluación preliminar?. Si la respuesta ha de ser que cualquiera, es decir, no sólo las de los anexos II y III, entonces no se entiende cuál es la función propia de estos anexos, pues el filtro determinante de las actuaciones que hayan de evaluarse ambientalmente ya no vendría constituido por la enumeración de proyectos que estos recogen, sino que estaría en la evaluación preliminar. Por el contrario, si la respuesta ha de ser que únicamente las actuaciones señaladas en lo anexos, entonces lo que no se entiende es cómo encaja la evaluación preliminar con la prescripción impuesta por estos anexos, por cuanto resultaría: por una lado, la existencia de unos anexos que contienen, en términos imperativos, una «relación de actuaciones que han de ser objeto de evaluación» (detallada o simplificada); pero, por otro lado, la existencia a la vez de una tercera modalidad de evaluación, la preliminar, que, con total desvinculación de los anexos, tendría capacidad para determinar el tipo de evaluación a realizar. Y no sólo eso, sino que, más aún, podría incluso llegar a sustituir a las propias evaluaciones detallada o simplificada, puesto que el Decreto [norma provisional 8.1b)] otorga al Comité de Evaluaciones de Impacto Ambiental la facultad de proponer en base a ella la autorización del proyecto, no obstante su menor grado de profundización y menores exigencias.

Por otro lado, se debe contemplar también el Decreto desde una perspectiva externa, esto es, desde el punto de vista tanto de su encuadre en el marco de la normativa específica reguladora de las evaluaciones de impacto ambiental como, en general, de su incardinación en el ordenamiento jurídico interno. En relación a lo primero, cabe advertir que el Decreto autonómico apuntaba algunos desajustes respecto de la que era en ese momento la norma principal de referencia, la Directiva 1985/337/CEE; desajustes que, inevitablemente, se hicieron luego patentes en el momento posterior de incorporarse al ordenamiento interno el contenido de la norma europea por vía del dictado de la normativa básica estatal. De todos modos, ya se ha dicho más arriba que al tiempo de entrada en vigor del Decreto 4/1986 tal normativa estatal aún no había aparecido; ni siquiera había expirado, y estaba aún lejos de hacerlo, el plazo de transposición de la Directiva comunitaria. Por tal razón, remitimos los comentarios sobre la cuestión al próximo epígrafe de este trabajo. En 
cuanto a lo segundo, cabe plantear aquí una cuestión tan importante como es la relativa a la discutible suficiencia de título competencial autonómico para el dictado, en el momento en que lo fue, del Decreto 4/1986. No se debe olvidar, en este sentido, que la fundamentación de la norma autonómica en la materia «protección del medio ambiente» había de comportar necesariamente su inconstitucionalidad, pues en el año 1986 la competencias autonómicas sobre dicha materia quedaban preceptivamente limitadas (art. 148.1.9 de la Constitución) a la potestad ejecutiva ${ }^{14}$. Tal vez consciente del inestable terreno sobre el que se movía, el Decreto 4/1986 omitió en su exposición de motivos cualquier alusión a los títulos competenciales utilizados ${ }^{15}$. Y así, en la práctica, la cuestión pasó totalmente desapercibida, no suscitándose, a diferencia de lo ocurrido en alguna otra comunidad autónoma ${ }^{16}$, ninguna controversia al respecto.

\section{El Real Decreto Legislativo 1302/1986, de 28 de julio}

El Real Decreto Legislativo 1302/1986, de 28 de julio ${ }^{17}$, constituye, en el orden externo, la respuesta española a las exigencias impuestas por la Directiva

${ }^{14}$ La Comunidad Autónoma de las Islas Baleares se constituyo en el año 1983 (Ley Orgánica 2/1983, de 25 de febrero), siguiendo el procedimiento ordinario de los artículos 143 y 146 de la Constitución. No fue hasta el año 1992, con la Ley orgánica 9/1992, de 23 de diciembre, que sus competencias sobre protección del medio ambiente se ampliaron a la potestad normativa para el desarrollo de la legislación básica estatal y el dictado de normas adicionales de protección.

15 No sucede lo mismo, por contra, en el Decreto 85/2004, de 1 de octubre (que modifica en aspectos muy puntuales el Decreto 4/1986), cuya exposición de motivos no duda en manifestar la apoyatura de la norma en el artículo 11.7 del Estatuto de Autonomía. Esta disposición estatutaria, precisamente, es la que atribuye a la Comunidad Autónoma competencia para el desarrollo legislativo en materia de «Protección del medio ambiente. Normas adicionales de protección. Espacios Naturales protegidos. Ecología». Sin embargo, no puede pasarse por alto que el Decreto 85/2004 ha sido dictado una vez producida la ampliación competencial motivada por la citada Ley Orgánica 9/1992, y después también de sendas reformas estatutarias operadas posteriormente (leyes orgánicas 9/1994, de 24 de marzo, y 3/ 1999, de 8 de enero). En definitiva, pues, el nivel competencial que atribuye el artículo 11.7 invocado por el Decreto de 2004 no se corresponde en absoluto con el que se podía tener en el momento de dictarse el Decreto 4/1986.

${ }^{16}$ Nos referimos al caso de la Comunidad Autónoma de Extremadura reseñado en la nota 7. El Decreto 45/1991, de 16 de abril, de Medidas de Protección del Ecosistema fue anulado por la sentencia del Tribunal Superior de Justicia de Extremadura 16/1993, de 28 de enero, en base precisamente a razones de orden competencial. A juicio del Tribunal, el Decreto constituía el resultado del ejercicio de competencias normativas sobre el título constitucional «protección del medio ambiente»; y, sin embargo, resultaba a la vez que la Comunidad Autónoma carecía de esa potestad, puesto que al haberse constituido por la vía de los artículos 143 y 146 de la Constitución y no haberse llevado a efecto aún en el momento de dictarse la norma la reforma estatutaria, sus competencias quedaban limitadas al ejercicio de la potestad ejecutiva sobre la protección del medio ambiente. Cuando posteriormente el Decreto 25/ 1993, de 24 de febrero, convalidó el dictado en el año 1991, ninguna objeción se podía ya oponer, pues entre uno y otro la Ley Orgánica 9/1992, de 23 de diciembre, había ampliado las competencias estatutarias a nivel normativo, para el desarrollo de la legislación básica estatal y el dictado de normas adicionales de protección del medio ambiente.

17 Dictado en virtud de la autorización otorgada por la Ley 47/1985, de 27 de diciembre, de Bases de Delegación al Gobierno para la Aplicación del Derecho de las Comunidades Europeas. Posteriormente, el Real Decreto 1131/1988, de 30 de septiembre, aprobó el Reglamento ejecutivo de la norma legal. 
1985/337/CEE. En el orden interno, por su parte, se trata de legislación básica, dictada al amparo de la competencia definida en el artículo 149.1.23 de la Constitución; legislación, por tanto, que había de vincular a todas las comunidades autónomas a la hora del ejercicio de sus potestades normativas sobre la materia. Siendo esto así, no puede pasarse por alto que tal eficacia vinculante atribuida a la legislación estatal se desplegó, en el caso concreto de las Islas Baleares, sobre una situación inversa a la ordinaria, esto es, en una situación en que la norma del Estado no precedía, sino que sucedía, a la regulación autonómica. Este es un hecho que sin duda explica la desconexión existente entre una y otra regulación.

En su propósito de hacer efectiva la transposición al derecho interno de las disposiciones de la Directiva de 1985, el Real Decreto Legislativo 1302/ 1986 trata de reproducir el esquema de contenidos incorporados por la normativa comunitaria. Se ocupa primer lugar, así, de delimitar las actuaciones que hayan de quedar sometidas a evaluación de impacto ambiental. Son estas, según dispone el artículo 1 , todos «los proyectos, públicos o privados, consistentes en la realización de obras, instalaciones o de cualquier otra actividad comprendida en el anexo del presente Real Decreto Legislativo» ${ }^{18}$. En segundo lugar, la norma estatal regula el contenido mínimo que deben reunir los estudios de impacto ambiental (art. $2^{19}$ ). Y, en tercer lugar, se ocupa del procedimiento a seguir para la declaración de impacto ambiental (arts. 3 a $\left.6^{20}\right)$. La competencia para tal declaración se atribuye al órgano ambiental ${ }^{21}$, imponiéndose siempre, de forma previa, la obligación de someter el estudio de impacto ambiental a los trámites de información pública e informes de los organismos interesados (incluida en su caso la información transfronteriza), y, con posterioridad a la resolución, la obligación de hacer pública la declaración de impacto ambiental.

\footnotetext{
${ }^{18}$ El anexo reproduce la relación de actividades contenidas en el anexo I de la Directiva 1985/337/ $\mathrm{CEE}$, pero ampliado con otras tres que se toman del anexo II de la norma comunitaria. Resulta de este modo, pues, que el Real Decreto Legislativo de 1986 adopta, por lo que se refiere al anexo II de la Directiva, el sistema de listar los proyectos que hayan de ser objeto de evaluación de impacto ambiental, dejando de lado el sistema de fijación de criterios o umbrales. Como excepción a lo señalado en el artículo 1, la norma estatal exonera de la evaluación ambiental los diferentes supuestos de exclusión autorizados por los artículos 1 y 2 de la Directiva.

19 Véanse también los artículos 7 a 12 del Reglamento ejecutivo.

${ }^{20}$ Artículos 13 a 24 del Real Decreto 1131/1988, de 30 de septiembre.

${ }^{21}$ Se entiende por tal «el que ejerza estas funciones (ambientales)en la administración pública donde resida la competencia sustantiva para la realización o autorización del proyecto». No obstante, se establece una regla para los casos de conflicto entre el órgano ambiental y el titular de la competencia sustantiva: «en caso de discrepancia entre ambos órganos resolverá el Consejo de Ministros o el órgano de Gobierno de la Comunidad Autónoma correspondiente, según la Administración que haya tramitado el expediente». La interpretación de esta regla en el ámbito de la Comunidad Autónoma ha dado lugar a una variante particular, consistente en entender que corresponde al pleno del Consejo Insular la competencia resolutoria en caso de conflicto, pero siempre que se trate de actuaciones cuya autorización corresponde al mismo Consejo Insular en el ejercicio de competencias transferidas por la Comunidad Autónoma al amparo de lo dispuesto en el artículo 39 del Estatuto de Autonomía.
} 
Fuera de lo establecido en la Directiva, la regulación del Real Decreto Legislativo incorpora también, finalmente, un aspecto nuevo muy importante, cual es el relativo al seguimiento y vigilancia del cumplimiento de la declaración de impacto ambiental. Con previsión expresa, a modo de medida cautelar, de la posibilidad de acordar la suspensión de aquellas actuaciones cuya ejecución se hubiera iniciado sin cumplimentar el trámite preceptivo de evaluación de impacto ambiental; e igualmente, en estos casos, de imponer al promotor la restitución de la realidad física alterada y la indemnización de los daños y perjuicios ocasionados (arts. 7, 9 y $10^{22}$ ).

\section{El defectuoso encaje de la normativa autonómica en el marco comunitario y estatal}

A) Con la entrada en vigor de la legislación básica estatal quedaba definitivamente completado en las Islas Baleares el marco normativo de las evaluaciones de impacto ambiental, estructurado en los tres niveles que se han visto, comunitario, estatal y autonómico. De este modo, el Decreto 4/1986 contaba finalmente con un claro marco de referencia en el que debía integrarse. Se estaba en condiciones, pues, de dar el nuevo paso ya anunciado en la exposición de motivos de la norma autonómica, esto es, de sustituir las «normas provisionales» por una regulación definitiva que se acomodara perfectamente a las exigencias dispuestas por la Directiva y la Ley básica estatal. Para ello, obviamente, la primera operación había de ser la de cotejar ambas regulaciones, al objeto de detectar o poner de manifiesto los eventuales puntos de divergencia. Ya se ha dicho antes que tales divergencias o desajustes existían; y, efectivamente, podrían señalarse diversos puntos de colisión.

De entrada, debemos recordar que el Decreto autonómico limitaba la exigencia de evaluación de impacto ambiental a aquellas actuaciones que, teniendo o pudiendo tener repercusiones significativas sobre el medio ambiente, fueran promovidas, subvencionadas o hubieran de autorizarse por la Administración de la Comunidad Autónoma. Tal limitación de orden subjetivo en el ámbito de aplicación de la norma no existe, por el contrario, ni en la Directiva ni en el Real Decreto Legislativo, cuyas exigencias respecto de los estudios de impacto ambiental se prescriben de cualesquiera actuaciones sometidas a la intervención previa de la Administración Pública, sin distinción alguna de categorías dentro de ésta. Cabe mencionar también, en segundo lugar, la falta de correspondencia que se observa en la enumeración, recogida en los correspondientes anexos, de las distintas actuaciones que deben quedar sometidas a estudio de impacto ambiental. Así, algunas de las actuaciones recogidas en anexo I de la Directiva y anexo del Real Decreto Legislativo no aparecen en los anexos II y III del Decreto 4/1986. Y, peor aún, cuando aparecen lo hacen en todo caso bajo condición resolutoria, pues con-

\footnotetext{
${ }^{22}$ Artículos 25 a 29 del Real Decreto 1131/1988, de 30 de septiembre.
} 
viene recordar que el Decreto 4/1986 permite, al amparo de un estudio preliminar, exonerar de evaluación detallada o simplificada a cualquiera de las actuaciones de los anexos II y III. En otras ocasiones, por su parte, la divergencia no se encuentra tanto en la definición de las actuaciones objeto de estudio de impacto ambiental como en el tipo de evaluación que haya de llevarse a efecto. Directiva comunitaria y norma básica estatal establecen una única modalidad de estudio de impacto ambiental, para la cual se imponen un mínimo de exigencias en cuanto a su contenido. Por el contrario, ya se ha visto, el Decreto 4/1986 admite dos tipos de evaluaciones definitivas, la detallada (anexo II), que parece ajustarse correctamente a las exigencias de la normativa europea y estatal, y la simplificada (anexo III), que se define por su menor grado de profundización y menores exigencias de contenido. Es evidente que la existencia de esta segunda modalidad de estudio de impacto ambiental no constituye, por si sola, un factor de desajuste, siempre y cuando la misma pudiera presentarse como un elemento adicional de protección; es decir, en el caso de prescribirse para actuaciones no recogidas en los anexos de la Directiva y el Real Decreto Legislativo. En otro caso, si resulta, como sucede, que actuaciones que la norma básica estatal sujeta a estudio de impacto ambiental quedan en la norma autonómica sometidas a evaluación simplificada, y no detallada, entonces sí que puede decirse que falta una correcta adecuación de la segunda a la primera. Por último, cabe señalar la existencia también de discrepancias de orden adjetivo, referidas al procedimiento de evaluación de impacto ambiental. Tanto la Directiva como el Real Decreto Legislativo imponen en todo caso la obligación de someter a información pública la evaluación de impacto ambiental, sin posibilidad de excepción alguna, a diferencia de lo que sucede con el Decreto 4/1986. Asimismo, norma comunitaria y estatal exigen que la exposición pública se practique sobre la totalidad del estudio, y no únicamente sobre una de sus partes, el documento de síntesis, tal como dispone la normativa autonómica. Finalmente, Directiva y Real Decreto Legislativo obligan a dar publicidad a la declaración de impacto ambiental, lo que no sucede en el caso del Decreto 4/1986, que sólo prescribe que el dictamen de impacto ambiental sea elevado al departamento promotor.

Establecido todo lo anterior, quedaría aún otra operación a realizar, la de confrontar el contenido de los dos bloques de regulaciones al efecto de identificar eventuales insuficiencias de la normativa autonómica respecto de la estatal y comunitaria. Y, en este orden, es evidente que faltaba al Decreto 4/ 1986 la incorporación, en desarrollo de Real Decreto Legislativo estatal, de todo el régimen de vigilancia y responsabilidad en el cumplimento de las declaraciones de impacto ambiental que éste había introducido.

Con todos estos argumentos, en fin, no cabía dudar sobre la necesidad de actualizar la normativa del Decreto 4/1986; de sustituir las «normas provisionales» y establecer una regulación de las evaluaciones de impacto ambiental conforme con el nuevo marco sobrevenido al Decreto autonómico. Sin em- 
LA EVALUACIÓN DE IMPACTO AMBIENTAL EN LAS ISLAS BALEARES: LA NORMATIVA...

bargo, esto no sucedió, y el Decreto siguió rigiendo en su condición interina y sin sufrir alteración alguna durante veinte años, hasta su reciente derogación en 2006.

B) La crítica hecha al Decreto, aún siendo del todo merecida, no exime sin embargo de la obligación de reconocer a éste algunos importantes aciertos, algunas mejoras notables respecto de la normativa básica estatal, especialmente en lo que hace referencia a la delimitación, en número y modo, de las actuaciones sometidas a estudio de impacto ambiental. Ha quedado dicho en su momento que el Real Decreto Legislativo 1302/1986 se limitó, básicamente, a reproducir el anexo I de la Directiva, apenas ampliado con la inclusión en la lista estatal de tres categorías de actuaciones tomadas del anexo II de la norma comunitaria. Todas las restantes actuaciones del citado anexo II quedaron directamente excluidas, pues, de la regulación estatal, que no previó ni siquiera para ellas —obviando así la línea apuntada por la Directiva- la fijación de umbrales o criterios determinantes de su sujeción a evaluación de impacto ambiental ${ }^{23}$. En este sentido, el Decreto 4/1986 resulta mucho más acertado, pues amplia considerablemente, en relación a la norma estatal, el elenco de actuaciones sometidas a evaluación, a la vez que incorpora, al efecto de la delimitación de tales actuaciones, la fijación de criterios o umbrales reveladores de sus potenciales repercusiones ambientales. Mención específica merecen, entre las actuaciones ampliadas por el Decreto 4/1986, las relacionadas con la planificación. El Decreto autonómico, en efecto, transciende el nivel de la proyección de obras para someter también a estudio de impacto ambiental determinadas categorías de planes. En concreto, el apartado 6.1 del anexo II exige evaluación de impacto ambiental simplificada para los «Planes Generales, Normas Subsidiarias, Planes Parciales y Especiales, incluida la revisión y/o adaptación del planeamiento». Sin desconocer la importancia de esta previsión, que se sitúa en la línea de las actuales exigencias de evaluación estratégica, lo cierto es, sin embargo, que la misma no ha desplegado en la Comunidad Autónoma todo el juego que cabía en principio esperar: por una lado, se trata de una previsión ciertamente limitada, que de forma incomprensible deja fuera a los planes de ordenación territorial ${ }^{24}$, y de la cual se ha hecho una interpretación sumamente restrictiva ${ }^{25}$; por otro lado, amén de lo anterior, ha sido frecuente en la práctica

\footnotetext{
${ }^{23}$ Este modo de proceder, excluyendo en bloque categorías de actuaciones de la Directiva, fue el que motivó, en el año 1999, la demanda interpuesta por la Comisión Europea contra el Reino de España, y el que obligó luego al Estado español, en el año 2000, a una clara rectificación de su planteamiento inicial, traducida en el Decreto-ley 9/2000, de 3 de marzo.

${ }^{24}$ Estos planes sí que se han recogido en la normativa de otras comunidades autónomas. Véase en este sentido la citada en la nota 7 de las comunidades de Cantabria y el País Vasco. También de algún modo la normativa de la Comunidad Autónoma de Andalucía.

25 Véase al respecto la sentencia del Tribunal Superior de Justicia de las Islas Baleares de 31 de mayo de 2004, que excluye del ámbito de aplicación del Decreto unas normas subsidiarias provisionales aprobadas por la Comisión Insular de Urbanismo del Consejo Insular de Mallorca conforme a lo previsto en el artículo 51 del Texto Refundido de la Ley sobre Régimen del Suelo y Ordenación Urbana de
} 
administrativa la exoneración del planeamiento urbanístico de la sumisión a evaluación ambiental.

C) Finalmente, ligado a lo dicho en el párrafo anterior, se plantea respecto al Decreto 4/1986 otra cuestión relevante: la relativa a la suficiencia de su rango para adicionar a la legislación estatal supuestos de sujeción a la evaluación de impacto ambiental (aún cuando ésta fuera en su forma simplificada). Es aquí, entonces, donde debe traerse a colación lo señalado por la jurisprudencia ${ }^{26}$ en relación a la posibilidad de las comunidades autónomas de ampliar los supuestos de sumisión a estudio de impacto ambiental, recordando que tal posibilidad tiene perfecto amparo en la competencia normativa autonómica de desarrollo en materia de protección del medio ambiente, pero con la exigencia de que se haga efectiva por norma que tenga rango de ley. Así las cosas, había aún que sumar otro motivo que obligaba a la revisión de la regulación autonómica de las evaluaciones de impacto ambiental.

\section{SEGUNDA ETAPA: LA EVALUACION DE PROYECTOS. LA MODIFICACION DE LA NORMATIVA COMUNITARIA, ESTATAL Y AUTONOMICA}

\section{La Directiva $1997 / 11 / C E$, de 3 de marzo}

La Directiva 1997/11/CE del Consejo, de 3 de marzo, va a introducir importantes novedades en la anterior Directiva de 1985, obligando en consecuencia a los estados miembros a afrontar otra vez el proceso de modificación de sus ordenamientos interno ${ }^{27}$. Las principales modificaciones que esta Directiva incorpora al régimen de las evaluaciones de impacto ambiental se pueden agrupar en tres grandes bloques diferenciados. El primer bloque afecta

\footnotetext{
1976. También la sentencia del Tribunal Superior de Justicia de las Islas Baleares de 3 de febrero de 2004, que excluye la aplicación del Decreto en el caso de un expediente de «modificación» del planeamiento urbanístico.

${ }^{26}$ Puede consultarse, por todas, la sentencia del Tribunal Supremo de 24 de octubre de 1996, donde se afirma que la potestad reglamentaria no alcanza ni a las limitaciones del derecho de propiedad, ni al establecimiento de cargas y obligaciones para los administrados, lo que sucede en los supuestos en que se impone la necesidad del estudio de impacto ambiental. En consecuencia, esta sentencia anula la previsión contenida en el Decreto aragonés 85/1990, de 5 de junio, de medidas urgentes de protección urbanística, cuyo artículo 4.2 exigía evaluación de impacto ambiental para cualquier transformación de la clasificación del suelo. Véase también, en el ámbito de la jurisprudencia menor, la sentencia del Tribunal Superior de Justicia de Extremadura de 26 de abril de 2005, que siguiendo la doctrina del Tribunal Supremo anula, por insuficiencia de rango, la previsión contenida en el Decreto autonómico 45/ 1991 que exigía estudio abreviado de impacto ambiental para la construcción de edificaciones fuera de la delimitación de suelo urbano. En la misma línea, sendas sentencias del Tribunal Superior de Justicia de Cantabria, de 4 de abril de 2002 y 28 de abril de 2003, que declaran la nulidad, respectivamente, del anexo II.6 («desguace o almacenamiento de chatarra») y II.8 («planes generales municipales, normas subsidiarias y complementarias de planeamiento, así como su modificación o revisión que afecten a suelos no urbanizables o que supongan alteración o implantación de uso global industrial en suelo urbanizable») del Decreto 50/1991, de 29 de abril,
}

${ }^{27}$ Para ello la Directiva de 1997 señala (art. 2), como fecha límite, el día 14 de marzo de 1999. 
LA EVALUACIÓN DE IMPACTO AMBIENTAL EN LAS ISLAS BALEARES: LA NORMATIVA...

al ámbito de aplicación de la Directiva (art. 4), destacando aquí sobremanera el notable incremento que experimenta la lista de actuaciones del anexo I; es decir, la enumeración de actuaciones que de forma sistemática han de someterse a la evaluación de impacto ambiental que regula la Directiva. En cuanto al anexo II, también éste se ve incrementado, tanto en el numero total de categorías relacionadas como en lo que se refiere al detalle de las concretas actuaciones recogidas dentro de cada una de ellas. No obstante, la principal novedad que afecta al anexo II es la que se refiere a la definición del modo en que los estados miembros hayan de determinar, de entre todas las actuaciones incluidas en la lista del anexo, cuáles queden sometidas a evaluación de sus repercusiones ambientales. La Directiva, acorde con la línea trazada por la jurisprudencia comunitaria, mantiene el sistema de fijación de umbrales, elimina el sistema de lista nacional y, finalmente, sustituye éste por el nuevo mecanismo de determinación o estudio caso por caso ${ }^{28}$. Y a todo ello añade, a la vez, la exigencia impuesta a los estados miembros de observar los diferentes criterios establecidos en el anexo III a la hora de resolver caso por caso o fijar los umbrales de las actuaciones que deban someterse a evaluación de impacto ambiental. El segundo bloque se refiere al contenido del estudio de impacto ambiental (art. 5). Como antecedente a la información que debe aportar el promotor del proyecto, la Directiva regula un tramite de consulta, en el que participan la autoridad competente para autorizar el proyecto, el promotor y las demás autoridades que han de expresar su opinión en el procedimiento, destinado a que la primera ofrezca al segundo su parecer sobre la información que deberá suministrar el estudio de impacto ambiental. En todo caso, la Directiva fija el contenido mínimo de la evaluación, incorporando con carácter preceptivo el estudio de alternativas y la justificación de la opción elegida. El tercer bloque, por último, afecta al procedimiento a seguir para la formulación de la declaración de impacto ambiental. Destaca en este orden, por una lado, toda la regulación relacionada con la información transfronteriza en los supuestos de actuaciones que tengan repercusiones sobre el medio ambiente de otros estados miembros, con previsión expresa de que el estado afectado pueda participar, a través de las autoridades y público nacional concernido, en el procedimiento de evaluación de impacto ambiental; y, por otro lado, la obligación que se impone a las autoridades de los diferentes estados miembros, no ya sólo — como en el régimen anteriorde informar al público del contenido de la decisión adoptada respecto del proyecto sometido a autorización y de las razones que apoyan dicha decisión, sino también de ofrecer una descripción de las medidas adoptadas (cuando éstas fueran precisas) para evitar, reducir y, si fuera posible, compensar los principales efectos negativos derivados de la actuación autorizada.

\footnotetext{
${ }^{28}$ La sentencia del Tribunal de Justicia de las Comunidades Europeas de 2 de mayo de 1996 se había pronunciado sobre la imposibilidad de los estados miembros de excluir anticipadamente del procedimiento de impacto ambiental bloques o grupos enteros de actuaciones incluidas en el anexo II. La práctica que se trataba de evitar era exactamente aquella en que había incurrido el Estado español con el Real Decreto Legislativo 1302/1986, y que fue a la postre la que motivo la demanda de la Comisión Europea de 14 de diciembre de 1999 a que se ha hecho referencia en la nota 23.
} 


\section{La revisión de la normativa básica estatal: el Real Decreto-ley 9/2000, de 6 de octubre, la Ley 6/2001, de 8 de mayo, y la Ley 62/2003, de 30 de diciembre, de medidas fiscales, administrativas y de orden social}

A) Las importantes reformas introducidas en la Directiva 1985/337/CEE van a obligar inevitablemente al Estado español, como antes ya se ha apuntado, a modificar su normativa sobre evaluaciones de impacto ambiental. No obstante, las sucesivas modificaciones operadas en este ámbito a través del Real Decreto-ley 9/2000, Ley 6/2001 y Ley 62/2003 no responden únicamente a esta circunstancia, sino también a otras razones que hacían necesario de igual modo la redefinición del marco normativo estatal básico. Y entre ellas, especialmente, la doctrina sentada por la sentencia del Tribunal Constitucional de 22 de enero de $1998^{29}$, que obligaba al Estado a dar mayor peso a las competencias ambientales autonómicas en los procesos de decisión referidos a actuaciones sometidas a la autorización estatal. Así pues, las reformas que introducen las distintas disposiciones citadas obedecen tanto a razones de consumo externo como a motivos de orden interno.

B) El grueso principal de las novedades que se incorporan al ordenamiento jurídico estatal viene dado, sin duda, por el Real Decreto-ley 9/2000, de 6 de octubre. Del doble orden de razones antes señaladas resulta, en definitiva, la modificación de los artículos 1, 2, 4.2, 5, 6 y 7 y del anexo I del Real Decreto Legislativo 1302/1986, así como la incorporación a éste de dos nuevos anexos, números II y III, y de una disposición adicional y otra final terceras. Todo este amplio conjunto de innovaciones puede concretarse, en todo caso, en cuatro grandes aspectos. En primer lugar, se aumenta notablemente el elenco de actuaciones que preceptivamente quedan sometidas a evaluación de impacto ambiental, lo cual se hace efectivo mediante la ampliación de la relación de proyectos recogidos en el anexo I. A la vez, se incorpora a la legislación estatal un nuevo anexo número II, destinado a enumerar aquellos otros bloques de actuaciones que no necesariamente se han de someter a evaluación de impacto ambiental, sino sólo cuando así lo determine, caso por caso, el órgano ambiental competente ${ }^{30}$, atendiendo a los distintos criterios enumerados en otro nuevo anexo que incorpora el Real Decreto-ley, el número III. En segundo lugar, por lo que se refiere al contenido mínimo exigido a las evaluaciones de impacto ambiental, se recoge la imposición comunitaria relativa al estudio necesario de alternativas y al deber de justificación en cada caso de la opción escogida. En tercer lugar, en el aspecto procedimental, se introduce el trámite de consulta, destinado a concretar el alcance del estudio de impacto ambiental; se regula también la obligación de los promotores de actuaciones del anexo II de ofrecer a la administración información suficiente para que ésta pueda resolver, en cada caso, sobre la necesi-

\footnotetext{
${ }^{29}$ Que resuelve el conflicto de competencias planteado a raíz de la aprobación del Reglamento de desarrollo del Real Decreto Legislativo 1302/1986.
} 
LA EVALUACIÓN DE IMPACTO AMBIENTAL EN LAS ISLAS BALEARES: LA NORMATIVA...

dad o no de someter el proyecto a evaluación de impacto ambiental; y, por último, se hace especial alusión a aquellos proyectos que puedan tener repercusiones sobre el medio ambiente de otros estados miembros, remitiéndose directamente entonces al cumplimiento de lo establecido en el Convenio sobre evaluación de impacto en el medio ambiente en un contexto transfronterizo ${ }^{31}$. En cuarto lugar, finalmente, el Real Decreto-ley de 2000 recoge una serie variada de disposiciones destinadas a facilitar la máxima colaboración y coordinación entre la diferentes administraciones públicas, con particular atención a la salvaguarda de las competencias autonómicas en los supuestos de actuaciones que deban ser autorizadas por el Estado ${ }^{32}$.

En cuanto a la Ley 6/2001, de 8 de mayo, el contenido de las novedades que ésta introduce queda básicamente circunscrito a la regulación del régimen sancionador, al margen de algunas modificaciones puntuales que se practican en los anexos I y II. Se introducen, así, dos nuevos artículos, 8 bis y 8 ter, destinados a la tipificación de infracciones en materia de evaluación de impacto ambiental de proyectos privados y al establecimiento de las correspondientes sanciones, respectivamente; todo ello, no obstante, sin perjuicio de las infracciones que pudieran definir las distintas comunidades autónomas.

Menores aún que en el supuesto anterior son las novedades aportadas por la Ley 62/2003, que se limita en esencia a la modificación puntual de los artículos 2.1.c) y 9 del Real Decreto Legislativo 1302/1986, para imponer a la evaluación de impacto ambiental el estudio de la interacción entre todos los factores afectados por las repercusiones del proyecto y para concretar el régimen de la medida cautelar de suspensión prevista en relación a la ejecución de determinadas actuaciones sometidas a estudio de impacto ambiental. Independientemente de lo anterior, no obstante, la Ley 62/2003 introduce también una nueva disposición adicional, la cuarta, en el Real Decreto Legislativo de 1986, referida específicamente a la evaluación de actuaciones que afecten a zonas de la Red Ecológica Europea «Natura 2000», y que conecta con lo dispuesto en los apartados 3 y 4 del artículo 6 del Real Decreto 1997/ 1995 , de 7 de diciembre, por el que se establecen medidas para contribuir a garantizar la biodiversidad mediante la conservación de los hábitats naturales y de la flora y fauna silvestres ${ }^{33}$.

\footnotetext{
${ }^{30}$ No obstante, el Real Decreto-ley 2000 dispone que las comunidades autónomas podrán establecer, bien la obligación de que las actuaciones (o algunas actuaciones) del anexo II sean siempre sometidas a evaluación de impacto ambiental, bien umbrales o criterios, más exigentes, determinantes de dicha sujeción a estudio de las repercusiones ambientales; añadiendo que en tales supuestos no será necesaria la determinación caso por caso.

${ }^{31}$ Hecho en Espoo (Finlandia) el 25 de febrero de 1991. Ratificado por España el día 1 de septiembre de 1997.

${ }^{32}$ Vgr., se establece la obligación del Estado de consultar siempre al órgano ambiental de la correspondiente Comunidad Autónoma en relación a los proyectos sometidos a declaración de impacto ambiental estatal que deban ubicarse en el territorio autonómico.

${ }^{33}$ En el ámbito de la Comunidad Autónoma de las Islas Baleares lo previsto en el artículo 6.3 y 4 del Real Decreto 1997/1995 y en la disposición adicional cuarta del Real Decreto Legislativo 1302/1986 se puede encontrar en el artículo 39 de la Ley 5/2005, de 26 de mayo, de conservación de los espacios de relevancia ambiental.
} 


\section{La nueva modificación de la normativa comunitaria y estatal: la Directiva 2003/35/CE, de 26 de mayo, y las leyes estatales 9/2006, de 28 de abril, y 27/2006, de 18 de julio}

A) La Directiva 2003/35/CE del Parlamento Europeo y del Consejo, de 26 de mayo, responde en su origen al compromiso de la Unión Europea de dar cumplimiento a las estipulaciones contenidas en el Convenio de Aarhus sobre el acceso a la información, la participación del público en la toma de decisiones y el acceso a la justicia en materia de medio ambiente. Constituye la Directiva, en este sentido, un instrumento de contribución a la aplicación de una parte importante de las obligaciones resultantes del mencionado Convenio, lo que se traduce en concreto, por una lado, en el establecimiento de disposiciones relativas a la participación del público en la elaboración de determinados planes y programas medioambientales, y, por otro lado, en la modificación de las Directivas 85/337/CEE y 96/61/CE ${ }^{34}$, con el propósito de mejorar los mecanismos de participación pública en los procesos de decisión relativos a las actuaciones contempladas en estas normas y, también, de incluir en ellas disposiciones sobre el acceso a la justicia a los efectos de impugnación de las decisiones adoptadas respecto de las señaladas actuaciones.

Por lo que se refiere en particular a la modificación operada en la Directiva de 1985, se pretende con ella asegurar la plena compatibilidad del contenido de la norma comunitaria con las disposiciones recogidas en el Convenio de Aarhus, especialmente lo señalado en sus artículos 6 (donde se establecen disposiciones relativas a la participación del público en los procesos de decisión sobre las concretas actividades que se enumeran en el anexo I y aquellas otras que, aún no enumeradas, puedan tener efectos significativos sobre el medio ambiente) y 9 , apartados 2 y 4 (donde se establecen disposiciones relativas a la posibilidad de entablar procedimientos administrativos o judiciales dirigidos a impugnar la legalidad de las acciones, decisiones $\mathrm{u}$ omisiones a las que se refiere la norma del artículo 6 sobre participación del público). El resultado, en definitiva, es la modificación en la Directiva 1985/337/CEE de los artículos 1 (apartado 2 y 4), 2 (apartado 3), 6 (apartados 2 y 3), 7 (apartados 1, 2 y 5) y 9; la adición de un nuevo artículo 10 bis; y, por último, la modificación de los anexos I y II. Como aspectos más destacados en los que se traducen todas estas modificaciones apuntadas se pueden señalar los siguientes. Por una lado, se refuerzan los requerimientos impuestos a los estados miembros en los casos, excepcionales, en que se excluya por éstos la aplicación de la Directiva de 1985 a todo o parte de un proyecto específico (art. 2). Por otro lado, se incrementa el contenido de la información que debe ponerse a disposición del público respecto de las actuaciones sometidas a estudio de impacto ambiental (art. 6), imponiéndose a los estados miembros el establecimiento de plazos razonables para hacer efectiva dicha

\footnotetext{
${ }^{34}$ Directiva 96/61/CE del Consejo, de 24 de septiembre, relativa a la prevención y al control integrados de la contaminación.
} 
información y la participación pública en el proceso de decisión medioambiental ${ }^{35}$. En tercer lugar, se da mayor detalle al régimen de la información transfronteriza prevista para los supuestos de actuaciones que puedan tener repercusiones sobre el medio ambiente de otro estado miembro (art. 7). Se amplia, en cuarto lugar, el contenido de la información que debe ponerse a disposición del público una vez adoptada la decisión relativa a la actuación objeto de autorización (art.9). Y, finalmente, se incorpora (art. 10 bis) una referencia expresa a la obligación de los estados miembros de garantizar la posibilidad de impugnación de las decisiones que repercutan sobre el medio ambiente.

B) El contenido de la Ley 9/2006, de 28 de abril, sobre evaluación de los efectos de determinados planes y programas sobre el medio ambiente, conecta, como su título pone de manifiesto, con una finalidad u objeto distinto al propio de la Directiva 1985/337/CEE, referida a la evaluación de proyectos. Por esta razón, el examen de la citada ley habrá de abordarse con detalle en un momento posterior, cuando se haga referencia a la denominada «evaluación estratégica». Sin embargo, la cita también aquí de la Ley 9/ 2006 tiene una parte importante de sentido que no puede obviarse, pues su disposición final primera introduce algunas innovaciones significativas en el Real Decreto Legislativo 1302/1986. Estas modificaciones, no obstante, no responden al propósito de adaptar la legislación estatal a la última regulación establecida por la Directiva 2003/35/CE antes vista (de ello se habría de encargar la Ley 27/2006 que se tratará en el apartado siguiente), sino que su referente hay que buscarlo más atrás, aún en la Directiva 1997/11/CE. La Ley 9/2006, así pues, trata de cerrar definitivamente el proceso de adaptación del ordenamiento interno a las exigencias de esta Directiva, culminando de este modo el proceso que había motivado el dictado del Real Decreto-ley 9/2000 y de la Ley 6/2001 (con el complemento de la Ley 62/2003) ${ }^{36}$. Con ello, se entiende que las modificaciones que se introducen afecten a un amplio espectro de los contenidos del Real Decreto Legislativo 1302/1986 ${ }^{37}$.

\footnotetext{
${ }^{35} \mathrm{El}$ artículo 6 distingue entre público (apartado 2) y público interesado (apartado 3), señalando para uno y otro el contenido de la información que debe ser puesta a su disposición. La definición de ambos conceptos aparece recogida en la lista de definiciones del artículo 12 .

${ }^{36} \mathrm{El}$ dictado de estas tres normas legales vino motivado en buena parte por la demanda interpuesta por la Comisión Europea contra España, en fecha 15 de septiembre de 2000, por falta de transposición de la Directiva 1997/11/CE. La aparición de las normas, sin embargo, no sirvió para poner fin a las controversias entre el estado español y la institución comunitaria, pues en fecha 27 de julio de 2004 ésta volvió a interponer demanda contra el Reino de España por incompleta incorporación de los contenidos de la Directiva. Finalmente, estando a punto de ver la luz la Ley 9/2006, el Tribunal de Justicia de las Comunidades Europeas ha dictado sentencia, en fecha 16 de marzo de 2006, declarando el incumplimiento en diversos aspectos de la Directiva por parte de España.

37 A saber: i) se consagra definitivamente la exigencia (ya introducida por la Ley 62/2003) de que el estudio de impacto ambiental evalúe la interacción entre los diferentes factores (suelo, agua, aire, etcétera) afectados por el proyecto; ii) se regula, ampliándolo, el contenido de la documentación que deberán presentar ante el órgano sustantivo los promotores de proyectos comprendidos en los anexos I y II, al efecto de su posterior remisión al órgano ambiental y el inicio, en su caso, del trámite de evaluación de impacto ambiental; iii) se define el trámite de consultas del órgano ambiental con las distintas ad-
} 
C) La Ley 27/2006, de 18 de julio, por la que se regulan los derechos de acceso a la información, de participación pública y de acceso a la justicia en materia de medio ambiente, tiene como objeto, y así se expresa textualmente en su exposición de motivos, definir el marco jurídico que permita dar respuesta a los compromisos asumidos por el Estado español en virtud del Convenio de Aarhus y, a la vez, incorporar al ordenamiento interno el contenido de las Directivas 2003/4/CE y 2003/35/CE. En este sentido, pues, las modificaciones que la Ley 27/2006 introduce en el Real Decreto Legislativo 1302/1986 representan sólo una pequeña parte del propósito de la ley, que se justifican por la necesidad de transponer al ordenamiento interno las modificaciones practicadas por la Directiva 2003/35/CE en el contenido de la Directiva 1985/337/CEE. Es decir, por la necesidad de adecuar la regulación estatal del procedimiento de evaluación de impacto ambiental (de proyectos) a las reglas sobre participación pública que, dimanantes del Convenio de Aarhus, el legislador comunitario asumió a través de la modificación de la Directiva de 1985 que llevó a cabo la de 2003.

Circunscrita aquí la atención de la Ley 27/2006 exclusivamente a aquello que incide directamente sobre la regulación del Real Decreto Legislativo 1302/1986, los principales contenidos de aquélla se concretan en la modificación de las disposiciones siguientes de éste. En primer lugar, el artículo 3, en el que se regula la participación del «publico» y del «público interesado» ${ }^{38}$ en los procedimientos referidos a la autorización de proyectos sometidos a evaluación de impacto ambiental. En segundo lugar, el artículo 6, destinado a regular el procedimiento de consulta transfronteriza. En tercer lugar, la disposición adicional segunda, que recoge la facultad atribuida al Consejo de Ministros, en caso de actuaciones sometidas a la Administración General del Estado, o al órgano que determine la legislación de las comunidades autónomas, si se tratara de proyectos sujetos a la autorización de éstas, para excluir una actuación determinada del trámite de evaluación de impacto ambiental. Y, en cuarto lugar, los anexos I y II, principalmente al efecto de incluir en su respectivo ámbito de aplicación determinadas modificaciones o ampliaciones de proyectos ya autorizados.

\footnotetext{
ministraciones afectadas (ampliable en su caso a otras personas físicas o jurídicas vinculadas a la protección del medio ambiente); iv) se establece la fijación de plazos máximos para el cumplimiento del trámite de información pública del estudio de impacto ambiental; v) se incorpora el trámite de informes sobre la evaluación de impacto ambiental que deberán emitir las administraciones afectadas, al tiempo de practicarse la información pública; vi) se prevé la caducidad de la declaración de impacto ambiental en el caso de no haberse iniciado la ejecución del proyecto en los plazos establecidos; vii) se establece la obligación fundamental de hacer pública la decisión adoptada sobre la aprobación del proyecto, así como la obligación de poner a disposición del público determinada información en relación a dicha decisión; y viii) finalmente, se introducen algunas modificaciones en los anexos I y II, variando la redacción referida a determinadas actuaciones o incorporando nuevas categorías de proyectos.

38 La Ley, siguiendo la terminología más propia del Derecho interno, distingue entre «público» y «personas interesadas». La definición de estos conceptos se recoge en un nuevo artículo 1 bis que se introduce en el Real Decreto Legislativo 1302/1986.
} 


\section{La revisión inexistente del régimen autonómico: el Decreto 85/2004, de 1 de octubre}

A) El Decreto 85/2004, de 1 de octubre, representa la primera - y a la postre única- modificación que se va a introducir en el régimen del Decreto $4 / 1986$ desde que éste entrara en vigor. Significa ello, de entrada, que las denominadas «normas provisionales» que el Decreto de 1986 establecía, nacidas con manifestada vocación de interinidad, lograron sobrevivir intactas más de dieciocho años; firmes, pues, contra la marea de toda la normativa comunitaria y estatal, sobrevenida ya en su mayor parte en el año 2004. Sin duda este es un primer dato a tener en cuenta, claramente revelador de la despreocupación de la administración autonómica en lo referente a las evaluaciones de impacto ambiental. De este modo, en definitiva, en el tiempo señalado de algo más de dieciocho años la Comunidad Autónoma de las Islas Baleares había logrado el hito de pasar de una neta posición de vanguardia a una situación de última retaguardia, de absoluta cola del pelotón; y, lo peor con todo ello, a una situación de total desajuste con el régimen definido por el derecho comunitario y estatal.

No obstante, la aparición del Decreto 85/2004 parecía anunciar un punto de inflexión, el propósito de recuperar el tiempo perdido, de poner en hora, en fin, el reloj del régimen autonómico. Nada más lejos de la realidad, tristemente. La simple lectura de la exposición de motivos de la norma adelanta un panorama desalentador. Según se expresa en ella, cuatro son las urgencias inaplazables que hacen necesaria «de forma inmediata» la reforma del Decreto 4/1986. A saber. Primera, la ampliación del plazo señalado al Comité de Evaluaciones de Impacto Ambiental para la emisión del dictamen de impacto ambiental. Segunda, la corrección de las discrepancias observadas entre la versión catalana y castellana en la redacción del apartado 5.9 del anexo III. Tercera, la inclusión de la participación de los promotores de los proyectos y de los ayuntamientos afectados en las reuniones del Comité de Evaluaciones de Impacto Ambiental. Y cuarta, la incorporación de un informe jurídico relativo a cada expediente sometido a dictamen del Comité. Por su parte, cualquier alusión a la necesidad de modificar la regulación autonómica como resultado de las importantes innovaciones introducidas por la normativa comunitaria y estatal sobrevenida queda totalmente diluida. Absolutamente ninguna mención a estas normas aparece hecha en la exposición de motivos, que resuelve despachar el tema con una vaga y despreocupada remisión a «una futura regulación completa por parte de la Comunidad $\mathrm{Au}$ tónoma de las evaluaciones de impacto ambiental mediante ley o decreto».

Con estos prolegómenos, es fácil imaginar que el contenido del Decreto $85 / 2004$ no podía ser más que insatisfactorio. Tal como quedaba dicho en la exposición de motivos, el Decreto acomete las cuatro modificaciones anunciadas. Pero a ellas añade otros dos que no habían sido anticipadas, irrelevante la primera en el mejor de los casos y claramente desafortunada la se- 
gunda. Por una lado, se introducía en el Decreto 4/1986 un nuevo artículo 3 bis, que se limitaba a señalar la facultad del órgano ambiental de emitir, amén de los dictámenes de impacto ambiental, los informes que pudieran solicitar otras administraciones públicas sobre actuaciones no incluidas en los anexos II y III. Por otro lado, se introducía también otro nuevo artículo, 7 bis, en el que se disponía que las actividades sujetas a evaluación de acuerdo con los anexos II y III no podrían ser objeto de exoneración de la realización del estudio de impacto ambiental; sin embargo, acto seguido la norma se desentendía de lo dicho, afirmando que quedarían exceptuadas de la prohibición aquellas actividades para las cuales se solicitase la exoneración «en base a una memoria ambiental que caracterice la actuación, las circunstancias medioambientales, y un análisis ambiental básico, que acredite la inexistencia de impactos significativos o su escasa importancia».

B) Con todo lo expuesto, es evidente que el Decreto 85/2004 no contribuye en nada, sino todo lo contrario, a remediar la preocupante situación del régimen de las evaluaciones de impacto ambiental en las Islas Baleares. A las deficiencias imputables al Decreto 4/1986 en relación a la versión originaria de la Directiva 1985/337/CEE y del Real Decreto Legislativo 1302/1986 habría que sumar, más tarde, la nuevas insuficiencias provocadas por la falta de adecuación a los cambios sobrevenidos en estas normas y, por último, agregar a todo ello los desaciertos del propio Decreto 85/2004. El resultado, un régimen totalmente desfasado que hacía que la situación fuera insostenible por más tiempo. Sin embargo, aún habría que esperar dos años más - como se verá más adelante- para encontrar una reforma de calado del sistema. Hasta entonces subsistirían las ya crónicas deficiencias del Decreto 4/1986. Así, los estudios de impacto ambiental seguían limitados a aquellas actuaciones promovidas, subvencionadas o sujetas a autorización de la Administración de la Comunidad Autónoma, sin referencia alguna a la necesidad de sujetar también a evaluación medioambiental las actuaciones sometidas a las entidades de la Administración Local. Por otra parte, se establecía un sistema de doble modalidad de evaluación de impacto ambiental, la detallada y la simplificada, sin imponer sin embargo en ambos casos el cumplimiento de los contenidos mínimos exigidos a los estudios de impacto ambiental por la normativa comunitaria y estatal. Esto, unido a la falta de correspondencia entre los anexos II y III del Decreto 4/1986 y I y II de la Directiva de 1985 y del Real Decreto Legislativo de 1986, podía provocar -y en la práctica provocaba - que actuaciones sujetas a la modalidad única de evaluación de impacto ambiental regulada en la norma comunitaria y estatal fueran finalmente sometidas a la modalidad simplificada autonómica menos exigente. Peor aún que lo anterior, el Decreto dejaba fuera de la exigencia de evaluación de impacto ambiental actuaciones preceptivamente sometidas a ella por la normativa comunitaria y estatal. Esta situación, que ya se había detectado en la versión inicial del Decreto 4/1986, se vio luego notablemente acentuada como consecuencia inevitable de las significativas ampliaciones practicadas en el anexo I de la Directiva comunitaria, prime- 
ro, y del Real Decreto Legislativo, después. Asimismo, la norma autonómica reducía toda la preocupación de la participación publica en el procedimiento de evaluación a la simple mención del trámite de información al publico, desconociendo por completo las exigencias impuestas por la normativa comunitaria y estatal en cuanto al contenido de la información que, a tal efecto, hubiera de suministrarse al publico en general y, en particular, a las personas interesadas en la actuación objeto de autorización. Obviaba, por otro lado, toda referencia a la información que hubiera de facilitarse al publico respecto del contenido, condiciones y razones de la decisión adoptada en relación al proyecto sometido a evaluación de impacto ambiental, del mismo modo que tampoco contemplaba la exigencia de hacer pública la declaración de impacto ambiental. Más aún, carecía de regulación relativa al trámite de consultas previsto entre el promotor del proyecto y la autoridad responsable de la autorización para precisar el contenido de la información que aquél hubiera de aportar en relación a los diferentes extremos que forman el estudio de impacto ambiental. Y, como último detalle, el Decreto estaba falto también de toda previsión destinada al desarrollo del régimen estatal sobre infracciones y sanciones, así como del relativo al seguimiento y vigilancia del cumplimiento de las declaraciones de impacto ambiental.

Por si todo lo anterior fuera poco, quedaría aún por añadir el singular régimen de exoneración a la evaluación de impacto ambiental establecido en el Decreto. En su versión originaria, éste había permitido, sobre la base de la denominada «evaluación de impacto ambiental preliminar», la posibilidad de excluir el estudio de impacto ambiental respecto de cualquier proyecto recogido en los anexos II o III. Este régimen, claramente contradictorio con los sistemas de lista y umbrales que prescribía entonces la normativa comunitaria y estatal, pudo sin embargo cobrar algún sentido cuando en el año 1997 se produce la modificación de la normativa comunitaria y se da entrada al sistema de determinación caso por caso. No obstante, no puede pasarse por alto que tal sistema quedaba restringido en aquella normativa a las actuaciones del anexo II, es decir, a aquellas que no necesariamente hubieran de someterse a evaluación de impacto ambiental por imperativo del anexo I. De este modo, la previsión indiscriminada por parte del Decreto 4/1986 de que cualquiera de las actuaciones recogidas en los anexos II y III pudiera ser eximida del estudio de impacto ambiental en base a la simple evaluación preliminar no admitía compatibilidad alguna con las previsiones de la regulación comunitaria y estatal. Y, si bien esto podría excusarse en una normativa anterior a la entrada en vigor del Real Decreto Legislativo 1302/1986, lo que de ningún modo se alcanza a entender es la reiteración del error en el Decreto $85 / 2004$. 


\section{TERCERA ETAPA: LA EVALUACIÓN ESTRATÉGICA DE PLANES Y PROGRAMAS. LA NORMATIVA COMUNITARIA Y ESTATAL}

\section{La Directiva $2001 / 42 / C E$, de 27 de junio}

La época de finales del siglo XX y principios del nuevo siglo va a representar, en el ámbito del derecho comunitario de los estudios de impacto ambiental, el momento de conexión o de encuentro entre la regulación de la evaluación medioambiental de proyectos y la evaluación de planes y programas. De un lado, se estaba en este tiempo en plena fase de culminar el proceso de definición del régimen de la evaluación de proyectos; de completar, en fin, el periplo iniciado en la década de los años ochenta con la Directiva 1985/337/CEE y que, a fecha de hoy, tiene como último hito destacado a la Directiva 2003/35/CE. De otro lado, también era éste el tiempo que marcaba la puesta en marcha del proceso de fijación del nuevo régimen general de la evaluación medioambiental de los planes y programas; proceso que tiene en la aprobación de la Directiva 2001/42/CE del Parlamento Europeo y del Consejo, de 27 de junio, sobre evaluación de los efectos de determinados planes y programas en el medio ambiente, su referente formal de inicio ${ }^{39}$.

El núcleo central del contenido de la Directiva se puede concretar en dos aspectos fundamentales: por una parte, la delimitación del ámbito de aplicación de la evaluación estratégica, y, por otra, la definición del proceso de evaluación ambiental.

En cuanto a lo primero, el esquema que sigue la Directiva, expuesto en el artículo 3, es en esencia el mismo que el de la Directiva de 1985. Es decir, identificación, en primer lugar, de los planes y programas que necesariamente deben someterse a evaluación medioambiental ${ }^{40}$; remisión a los estados miembros, en segundo lugar, para que sean ellos los que determinen, caso por caso o mediante lista de categorías, la necesidad o no de realizar un estudio de impacto ambiental para aquellos otros planes y programas que la Directiva no somete preceptivamente a evaluación ${ }^{41} ; \mathrm{y}$, por último, exclusión de determinados planes y programas, a los cuales no les resulta de aplicación la Directiva ${ }^{42}$.

En cuanto a lo segundo, los artículos 4 a 9 definen el contenido de la evaluación medioambiental, entendida ésta como un proceso complejo formado

\footnotetext{
39 Ello no quiere decir, sin embargo, que la evaluación de planes y programas no contara con antecedentes conocidos en el derecho comunitario sectorial. Baste citar, a modo de ejemplo, lo prescrito en al artículo 6.3 de la Directiva 92/43/CEE del Consejo, de 21 de mayo, relativa a la conservación de los hábitats naturales y de la flora y fauna silvestres.

40 Apartados 2.a) y 2.b) del artículo 3.

41 Apartados 3 y 4 del artículo 3.

${ }^{42}$ Apartados 8 y 9 del artículo 3.
} 
LA EVALUACIÓN DE IMPACTO AMBIENTAL EN LAS ISLAS BALEARES: LA NORMATIVA...

por una pluralidad de actuaciones diversas, que, a su vez, deberán integrarse en el procedimiento específico para la aprobación del plan o programa o, en otro caso, formar un procedimiento independiente. De acuerdo con la Directiva, la evaluación medioambiental comprende las fases o trámites de informe medioambiental — que incluye el de consultas previas destinadas a fijar el contenido y alcance de la información que debe aportar el informe-, consultas (al público y a las autoridades, tanto nacionales como de otros estados, esto segundo en el caso de efectos transfronterizos), toma de decisión sobre la propuesta de plan o programa y, en último lugar, información sobre la decisión adoptada.

Finalmente, al margen de lo anterior, la exposición del contenido de la Directiva 2001/42/CE requiere una referencia a su ámbito temporal de aplicación. La cuestión aparece tratada en el artículo 13, que establece el día 21 de julio de 2004 como fecha límite para la incorporación del contenido de la Directiva al ordenamiento interno de los estados miembros; y, partiendo de esta fecha, dispone la obligación de someter a evaluación medioambiental todos los planes o programas cuyo primer acto preparatorio formal sea posterior al día 21 de julio de 2004 o, aún siendo anterior, no se hayan sometido a decisión aprobatoria transcurridos veinticuatro meses desde la fecha (lo que supone el día 21 de julio de 2006). Para este último supuesto, sin embargo, la Directiva prevé una posibilidad de excepción, pues admite que los estados miembros puedan excluir la exigencia de evaluación cuando se demuestre, caso por caso, que resulta inviable. Dicha decisión, en tal supuesto, deberá ponerse en conocimiento del público.

\section{La Ley 9/2006, de 28 de abril}

La Ley 9/2006, de 28 de abril, sobre evaluación de los efectos de determinados planes y programas en el medio ambiente constituye el instrumento normativo a través del cual se lleva a efecto la incorporación al ordenamiento jurídico interno estatal de las determinaciones establecidas por la Directiva 2001/42/CE. Su dictado responde fundamentalmente a la competencia del Estado sobre legislación básica en materia de protección del medio ambiente, si bien algunas disposiciones de la Ley carecen de ese carácter y constituyen la regulación aplicable de forma exclusiva y directa a la Administración General del Estado. Tal sucede con todo el contenido del título $\mathrm{III}^{43}$, destinado a particularizar para la Administración estatal el régimen general básico vinculante para el conjunto de las distintas administraciones públicas. De este modo, atendido el propósito de nuestro estudio, la referencias a la Ley 9/2006 se limitaran a aquellas que son de general aplicación y que,

\footnotetext{
43 Tampoco tienen carácter de normativa básica, según establece la disposición final tercera, el apartado segundo de la disposición adicional segunda, las disposiciones adicionales sexta y séptima y el apartado tercero de la disposición final cuarta. Todos estas normas son sólo aplicables a la Administración General del Estado y a sus organismos públicos.
} 
con ello, están llamadas a definir el marco jurídico dentro del cual deba moverse la regulación de la Comunidad Autónoma de las Islas Baleares.

Siguiendo el mismo esquema de la Directiva, la Ley 9/2006 se ocupa de las dos cuestiones esenciales tratadas por aquella: primero, de la delimitación del ámbito de aplicación de la evaluación estratégica (título I; artículos 3 y 4, principalmente) y, segundo, de la definición del procedimiento de evaluación medioambiental (título II, artículos 7 a 15).

Por lo que se refiere a la delimitación del ámbito de aplicación de la evaluación, la Ley 9/2006 reproduce la clasificación tripartita ya conocida, respectando las determinaciones contenidas en la directiva comunitaria: planes y programas que necesariamente se han de someter a evaluación medioambiental ${ }^{44}$; planes y programas que no se han de someter siempre a evaluación, sino sólo cuando así se determine caso por caso o mediante el establecimiento de una lista de tipos de planes, de acuerdo - en uno y otro supuesto- con los criterios enunciados en el anexo $\mathrm{III}^{45}$; y, en tercer lugar, planes y programas que quedan excluidos de la aplicación de la Ley y, en consecuencia, no quedan sometidos en ningún caso a la evaluación estratégica que esta prevét ${ }^{46}$.

En cuanto al procedimiento de evaluación medioambiental, la Ley 9/2006 establece que éste se integrará dentro del procedimiento previsto por la legislación específica para la elaboración del plan o programa. En otro caso, si no existiera tal previsión, las administraciones públicas deberán establecer el correspondiente procedimiento al efecto. Sea como fuere, la ley estatal prescribe para dicho procedimiento las mismas actuaciones que las previstas en la Directiva, incorporando simples variaciones terminológicas, en unos casos, pero también, en otros, algunas adiciones más significativas. Ejemplo de lo primero lo constituye el denominado informe de sostenibilidad ambiental, coincidente en cuanto función y contenido con el informe medioambiental que impone la Directiva. Respecto a lo segundo, cabe destacar la previsión de la memoria ambiental, como documento cuya finalidad es la de valorar la integración de los aspectos ambientales en la propuesta de plan o programa y que, sobre la base de todo lo actuado, es el encargado de fijar, previo a la toma de decisión, las determinaciones finales que deban incorporarse a la propuesta de plan o programa.

Finalmente, queda también hacer una alusión al régimen transitorio previsto en la Ley 9/2006 para los planes y programas iniciados con anterioridad a la fecha de su entrada en vigor. En este sentido, cabe decir que la norma estatal se ajusta perfectamente a las exigencias de la Directiva, haciendo girar toda la aplicación del régimen de la evaluación estratégica alrededor de las dos fechas señaladas por ésta, 21 de julio de 2004 y 21 de julio de 2006,

\footnotetext{
${ }^{44}$ Apartados 1 y 2 del artículo 3.

45 Apartado 3 del artículo 3.

46 Apartado 4 del artículo 3 y disposición transitoria segunda.
} 
y en el modo que ésta lo hace. Como aportación propia, la Ley 9/2006 define en el último párrafo de la disposición transitoria segunda la noción de «acto preparatorio formal».

\section{ETAPA FINAL: LA NUEVA REGULACION AUTONOMICA DE LA EVALUACION DE PROYECTOS Y PLANES}

\section{La Ley 11/2006, de 14 de septiembre. Consideraciones generales}

La incorporación sucesiva al ordenamiento comunitario, primero, y al ordenamiento estatal, después, de la nueva modalidad de evaluación medioambiental hacía ineludible la obligación de la Comunidad Autónoma de las Islas Baleares de incorporar también al propio ordenamiento autonómico el régimen de la evaluación estratégica. De ningún modo resultaban suficientes, a tal efecto, las mínimas referencias que el Decreto 4/1986 establecía respecto a la evaluación de determinados supuestos de planificación, pues es evidente que la regulación de la norma autonómica quedaba, en cuanto a la definición del ámbito de aplicación, contenido y procedimiento de la evaluación medioambiental, muy lejos de las exigencias impuestas a la evaluación estratégica por la legislación comunitaria y estatal ${ }^{47}$. El resultado de aquella obligación, en fin, es la Ley 11/2006, de 14 de septiembre, de evaluación de impacto ambiental y evaluaciones ambientales estratégicas en las Islas Baleares, mediante la cual se da cuerpo al régimen autonómico de la evaluación de planes y programas.

No obstante, la Ley no se limita, como su título deja entrever, a la evaluación estratégica, sino que se extiende también a la evaluación de impacto ambiental de proyectos. Por fin, pues, la necesidad de dar regulación a la nueva evaluación estratégica había favorecido aquello durante tantos años demandado y a lo cual el legislador autonómico se había resistido pertinazmente: la revisión, para su adecuación a la normativa comunitaria y estatal, del régimen de los estudios de impacto ambiental de proyectos ${ }^{48}$. De este modo, en definitiva, la Ley 11/2006 reúne en un solo texto legal ambas modalidades de evaluación, lo que constituye a nuestro entender un dato positivo, pues contribuye a dotar de sustantividad propia al mecanismo de la evaluación medioambiental.

\footnotetext{
${ }_{47}$ Desde este punto de vista, parece excesiva la afirmación contenida en la exposición de motivos de la Ley 11/2006: «El Decreto 4/1986, de 23 de enero, de implantación y regulación de los estudios de impacto ambiental, se adelanto veinte años al resto del Estado español, ya que incluía la evaluación de impacto ambiental del planeamiento urbanístico, lo que ha dotado a nuestra comunidad autónoma de una experiencia única con vistas a la evaluación estratégica».

${ }^{48}$ La disposición derogatoria única de la Ley 11/2006 dispone expresamente la derogación del Decreto $4 / 1986$, de 23 de enero.
} 
La Ley, extensa en su articulado, se estructura en tres títulos, de los cuales dos, el segundo y el tercero, se dedican de forma específica a regular el procedimiento de la evaluación de proyectos y de la evaluación de planes y programas, respectivamente. En el título primero, por su parte, se contienen las disposiciones generales, entre las que se incluyen, asimismo, las destinadas a delimitar el ámbito de aplicación de una y otra modalidades de evaluación medioambiental. Sobre este último extremo se volverá en el momento de analizar ambos tipos de evaluación; por ahora interesa destacar otros aspectos de los contenidos en el título primero. Cabe hacer especial hincapié, en primer lugar, en la proclamación del artículo 1, donde de forma expresa se extiende la evaluación de los proyectos, planes y programas que puedan tener efectos significativos sobre el medio ambiente a todos los que se elaboren, aprueben o autoricen por «la comunidad autónoma de las Islas Baleares, los consejos insulares o la administración local». De esta manera, por tanto, se pone fin a uno de los principales males que venía arrastrando la vigencia del Decreto 4/1986, cual era su limitación al ámbito de la administración autonómica. Por otra parte, destaca la importancia del peso atribuido a la evaluación ambiental que se traduce en la expresa sanción de nulidad que se asigna a las resoluciones que se adopten sin el preceptivo estudio de impacto ambiental o, también, «sin observar, total y absolutamente, los procedimientos de evaluación de impacto ambiental o de evaluación ambiental estratégica que regula esta ley» ${ }^{49}$. Se debe mencionar también, en tercer lugar, la consagración del principio de acción pública para exigir el cumplimiento de lo establecido en la ley ante los órganos administrativos y contencioso-administrativos, en los términos que dispone la legislación de acceso a la información, de participación pública y de acceso a la justicia ${ }^{50}$. Por último, se identifica el órgano ambiental de la Comunidad Autónoma de las Islas Baleares en relación a los proyectos, planes o programas que la ley somete a evaluación: la Comisión de Medio Ambiente de las Islas Baleares, asistida por un comité técnico de composición multidisciplinar creado en su seno ${ }^{51}$.

\footnotetext{
${ }^{49}$ Obsérvese que el último inciso trascrito invierte, no sabemos si consciente o inconscientemente, la regla del artículo 62.1.e) de la Ley 30/1992, de 26 de noviembre, de Régimen Jurídico de las Administraciones Públicas y del Procedimiento Administrativo Común, pues, tal como está redactado la ley autonómica, la sanción de nulidad será aplicable en cualquier supuesto de simple inobservancia del procedimiento establecido para la evaluación de impacto ambiental, sin necesidad de que la omisión afecte a las reglas esenciales del procedimiento. Se rectifica, de esta manera, la posición mantenida hasta ahora por el Tribunal Superior de Justicia de las Islas Baleares, que en diversos supuestos se había pronunciado (véanse las sentencias de 9 de abril y 29 de junio de 1999) sobre el vicio de nulidad relativa, o simple anulabilidad, que acarreaba la omisión del trámite de información pública de la evaluación de impacto ambiental.

50 Véanse los artículo 20 a 23 de la Ley estatal 27/2006, de 18 de julio.

${ }^{51}$ La organización, funciones y régimen jurídico de la comisión quedan diferidos a la regulación reglamentaria. A su vez, la disposición transitoria primera de la ley dispone que en tanto no se lleve a cabo dicha regulación, el órgano ambiental de la Comunidad Autónoma será la Comisión Balear de Medio Ambiente, creada y regulada por el conocido Decreto 38/1985, de 16 de mayo.
} 
LA EVALUACIÓN DE IMPACTO AMBIENTAL EN LAS ISLAS BALEARES: LA NORMATIVA...

\section{La evaluación de proyectos}

A) La Ley 11/2006 va a suponer, sin duda, un cambio radical en el diseño de la regulación autonómica de los estudios de impacto ambiental de proyectos, que afecta a todos sus aspectos esenciales: delimitación del ámbito de aplicación, contenido de la evaluación y procedimiento para llevarla a efecto. Desde que apareciera el Real Decreto Legislativo 1302/1986 las Islas Baleares van a poder contar, por primera vez en la historia de la autonomía, con una regulación que, sin ser absolutamente acorde en todo con el marco comunitario y estatal, sí se mueve al menos en la línea de éste.

B) Por lo que se refiere al ámbito de aplicación, la ley autonómica recoge el sistema de doble lista de la normativa comunitaria y estatal, distinguiendo, de un lado, las actuaciones que necesariamente se han de someter a evaluación de impacto ambiental por considerarse que de ellas pueden desprenderse efectos significativos sobre el medio ambiente (anexo I); y, de otro lado, las actuaciones que no se han de someter siempre a evaluación de impacto ambiental, sino sólo cuando así lo decida, en cada caso, el órgano ambiental (anexo II, a las cuales cabe añadir aquellas otras no incluidas en el anexo I que puedan afectar a los espacios de la Red Ecológica Europea Natura 2000).

Conviene destacar, relacionado con el contenido de los citados anexos, las notables variaciones que la ley autonómica practica respecto de los umbrales definidores de una parte importante de proyectos relacionados en los anexos I y II del Real Decreto Legislativo 1302/1986, con el resultado de aumentar, en relación a las previsiones de la norma estatal, el ámbito de supuestos que necesariamente han de someterse a evaluación de impacto ambiental. Este mismo resultado se obtiene, en otras ocasiones, incorporando directamente a los anexos de la ley autonómica supuestos no previstos en la normativa estatal. Como contrapartida a todo esto, sin embargo, cabe advertir también la ausencia en la Ley 11/2006 de determinadas categorías de proyectos que sí aparecen incluidos en los anexos de Real Decreto Legislativo de 1986.

A los supuestos de sujeción de los anexos I y II, la Ley 11/2006 adiciona un tercer bloque que viene a reforzar el régimen de la legislación básica estatal, disponiendo que deberán someterse igualmente a evaluación de impacto ambiental aquellas actuaciones que puedan tener repercusiones ambientales significativas para la cuales, a pesar no estar incluidas en los anexos I y II, así se haya dispuesto por la normativa sectorial (legal o reglamentaria) o por un instrumento de ordenación territorial o medioambiental debidamente aprobado por la administración correspondiente.

Por último, Ley 11/2006 cierra el sistema de delimitación del ámbito de aplicación de la evaluación de impacto ambiental por vía negativa, mediante la definición de dos supuestos de exclusión. En concreto, la Ley 11/2006 excepciona del procedimiento de evaluación medioambiental, en primer lu- 
gar, los proyectos que, en casos excepcionales y mediante acuerdo motivado, decida excluir el Consejo de Gobierno de la Comunidad Autónoma, a propuesta del Consejero de Medio Ambiente, previa petición del órgano sustantivo y con informe del órgano ambiental ${ }^{52}$; y, en segundo lugar, los proyectos que tengan que aprobarse específicamente mediante una ley del Parlamento de las Islas Baleares ${ }^{53}$.

Los distintos supuestos de sujeción a evaluación de impacto ambiental se complementan, por otra parte, con la figura del denominado «informe ambiental», que la ley autonómica prevé para diferentes casos. De un lado, dispone que se someterán a informe ambiental los proyectos para los cuales sea exigido dicho informe por la legislación sectorial o por el planeamiento territorial, medioambiental o sectorial ${ }^{54}$. De otro, establece que el órgano ambiental podrá disponer, motivadamente, que los proyectos del anexo II que no hayan de someterse a evaluación de impacto ambiental de acuerdo con los criterios de sujeción previstos ${ }^{55}$ sean objeto, no obstante, de un informe ambiental $^{56}$, que podrá incluso imponer la adopción de medidas correctoras,

${ }^{52}$ El acuerdo de exclusión adoptado por el Consejo de Gobierno se hará público, debiendo éste a la vez proceder conforme con las exigencias del artículo 13. Tales exigencias tienen su fundamento en la disposición adicional segunda del Real Decreto Legislativo 1302/1986 (en la redacción dada por la Ley 27/2006), si bien entre unas y otras se observan algunas divergencias significativas:

i) La norma estatal exige que el acuerdo de exclusión y las causas que lo justifican sean puestas a disposición de las personas interesadas, pero también que sean publicadas en el diario oficial correspondiente de la comunidad autónoma. Por el contrario, la Ley 11/2006 sólo alude a la necesidad de dar conocimiento a las personas interesadas.

ii) La ley estatal dispone que en todo caso deberá ponerse a disposición de las personas interesadas «la información relativa al examen sobre las formas alternativas de evaluación del proyecto excluido». La ley autonómica, por su parte, se muestra menos exigente, y después de señalar el deber de examinar la conveniencia de otras formas de evaluación afirma que corresponderá al Gobierno determinar «si es procedente hacer públicas las informaciones que se recogen».

Señalar, no obstante, que el artículo 13.2 de la Ley 11/2006 veta la posibilidad de exclusión en los casos de proyectos «que afecten a los espacios de la Red Ecológica Europea Natura 2000 y a los espacios protegidos al amparo de la Ley 5/2005, de 26 de mayo, de conservación de los espacios de relevancia ambiental, o de la Ley 4/1989, de 27 de marzo, de conservación de los espacios naturales y la flora y fauna silvestres».

${ }^{53}$ En este caso la divergencia respecto de la normativa básica estatal es aún mayor que en el caso anterior, pues tal posibilidad no se prevé en la disposición adicional segunda del Real Decreto Legislativo 1302/1986, que limita la exclusión a los proyectos que se aprueben mediante ley de las Cortes Generales.

${ }^{54}$ Este informe ambiental, al que se refiere el artículo 47, es distinto de la evaluación de impacto ambiental que, en su caso, pueda resultar impuesta por la normativa sectorial y por el planeamiento territorial o medioambiental. En este ultimo supuesto, al que alude el artículo 10.3, se seguirá el procedimiento de evaluación establecido con carácter general por la Ley 11/2006, en tanto que en el supuesto del artículo 47, éste se remite directamente a un procedimiento específico que se regula en el artículo 48.

${ }_{55}$ Estos criterios aparecen enumerados en el artículo 44 y coinciden con los recogidos en el anexo III de la Ley estatal 9/2006, de 28 de abril.

${ }^{56}$ La redacción de la Ley 11/2006 permite entender que este informe y el previsto en el artículo 47 (al que se ha hecho referencia en la nota 54) son distintos. Sin embargo, la Ley, a diferencia de aquel supuesto, no prevé aquí cuál haya de ser el contenido ni el procedimiento a través del cual se haya de articular el informe. 
protectoras y compensatorias ${ }^{57}$. Por último, la Ley completa el abanico de supuestos con una especie de cláusula residual, en virtud de la cual el órgano competente para autorizar cualquier proyecto o actividad podrá solicitar del órgano ambiental su parecer sobre la misma, aún cuando ésta no esté sometida a evaluación de acuerdo con la ley. Dicho parecer deberá versar sobre la conveniencia o no de autorizar el proyecto y, en su caso, sobre las medidas que deban adoptarse para minimizar los impactos negativos ${ }^{58}$.

B) El segundo aspecto fundamental de la Ley 11/2006 es el que hace referencia al contenido de la evaluación de impacto ambiental. Dicho contenido viene establecido, con carácter de mínimos, en el artículo $27^{59}$ de la ley, ajustándose en su mayor parte a las exigencias impuestas por el artículo 2 del Real Decreto Legislativo de 1986. No obstante, existen también en este ámbito algunas divergencias significativas. En este sentido, la ley autonómica no incluye en el contenido del estudio de impacto ambiental el informe destinado, en su caso, a señalar las dificultades informativas o técnicas encontradas en la elaboración del mismo. Y, mucho más importante que esto, la ley autonómica olvida por completo la exigencia de valorar la interacción entre los diferentes factores sobre los que se proyectan los efectos de la actuación sometida a evaluación. Esta omisión, que se hace patente con la simple comparación de los artículos dedicados en la norma estatal (art. 1) y en la norma autonómica (art. 9) a definir los objetivos de la evaluación de impacto ambiental ${ }^{60}$, constituye -como decimos- una deficiencia importante, pues no cabe olvidar que la misma omisión en su momento por parte del Real Decreto Legislativo de 1986 ha sido una de las razones que ha llevado al Tribunal de Justicia de las Comunidades Europeas a condenar al Estado español por incumplimiento de la Directiva comunitaria de $1985^{61}$.

\footnotetext{
57 Cuando se trate de proyectos no sometidos a evaluación de impacto ambiental de acuerdo con los criterios legales de sujeción, pero que afecten a zonas de la Red Natura 2000, entonces el eventual informe ambiental será sustituido por la preceptiva «evaluación de repercusiones» que regula el artículo 39 de la Ley 5/2005, de 26 de mayo, de conservación de los espacios de relevancia ambiental.

${ }^{58}$ La previsión de este informe aparece recogida en el artículo 15, que se remite, a efectos de su emisión, al procedimiento que regula el artículo 48

59 El último párrafo de este artículo dispone que reglamentariamente, mediante orden del consejero competente en materia de medio ambiente, se podrá desarrollar el contenido de los estudios de impacto ambiental.

60 El artículo 1 del Real Decreto Legislativo de 1986 establece que «la evaluación de impacto ambiental identificará, describirá y evaluará de forma apropiada, en función de cada caso particular y de conformidad con este real decreto legislativo, los efectos directos e indirectos de un proyecto sobre los siguientes factores: (...) d) la interacción entre los factores mencionados anteriormente». Por el contrario, el artículo 9 de la Ley 11/2006 se limita a señalar, con una redacción mucho más escueta, que «la evaluación de impacto ambiental identificará, describirá y evaluará de forma apropiada los efectos directos o indirectos de un proyecto sobre el medio ambiente, en función de cada caso particular y de conformidad con esta ley».

${ }^{61}$ Nos referimos a la sentencia de 16 de marzo de 2006 ya reseñada en la nota 36 . En realidad, el Estado español ya había reconocido su incumplimiento, pues la Ley 62/2003 tuvo precisamente como una de sus finalidades específicas introducir en la redacción del artículo 1 del Real Decreto Legislativo la referencia expresa a la valoración de la interacción entre los diferentes factores afectados por el proyecto sujeto a evaluación.
} 
C) El tercer gran aspecto que aborda la Ley 11/2006 es el relacionado con procedimiento de evaluación de impacto ambiental, distinguiendo dos cauces diferenciados según se trate de proyectos sometidos preceptivamente a evaluación medioambiental o, en otro caso, de proyectos cuya sujeción o no debe determinarse de forma particular por el órgano ambiental. En realidad, sin embargo, las diferencias sólo afectan a lo que podríamos denominar la etapa preliminar del procedimiento de evaluación, toda vez que, decidido en su caso que un proyecto del anexo II deba someterse a evaluación, la ley se remite entonces a los mismos trámites que los establecidos para los proyectos sometidos preceptivamente a estudio de sus repercusiones ambientales ${ }^{62}$.

Como antecedente a la iniciación del procedimiento de evaluación en sentido estricto, la ley regula una fase previa de consultas, cuya finalidad es la de determinar con precisión el alcance y grado de detalle que el estudio de impacto ambiental deberá ofrecer sobre los diferentes extremos que han de integrar su contenido. A tal efecto, el promotor del proyecto deberá presentar ante el órgano ambiental, por conducto del órgano sustantivo, un memoria-resumen del proyecto con el contenido que se específica en el artículo 22.1 de la norma legal ${ }^{63}$. Dicha documentación será puesta a disposición del público interesado y de las administraciones afectadas, con el objeto de que el órgano ambiental pueda mantener consultas con ellas ${ }^{64}$ (sin perjuicio de que pueda consultar también a otras personas, físicas o jurídicas, públicas o privadas, vinculadas a la protección del medio ambiente). Evacuadas las consultas, y en todo caso en el plazo máximo de un mes desde la solicitud de consulta, el órgano ambiental resolverá sobre el alcance de la información del estudio de impacto ambiental. Tal resolución, finalmente, será notificada al promotor, al objeto que pueda proceder a la elaboración del estudio de impacto ambiental.

Una vez elaborado el estudio, se estará ya en condiciones de iniciar el procedimiento de autorización del proyecto ${ }^{65}$, no así el de evaluación de sus

\footnotetext{
${ }^{62}$ Regulación separada se da al procedimiento para la emisión de los «informes ambientales» señalados en los artículos 15 y 47. Dicho procedimiento, regulado en el artículo 48, se inicia con la solicitud de informe por parte del órgano sustantivo, que debe ir acompañada de copia del proyecto y de una memoria ambiental en la que se caracterice la actuación y se contenga un análisis de los impactos del proyecto sobre el medio ambiente, las consideraciones ambientales a tener en cuanta y, en su caso, las medidas correctoras, protectoras o compensatorias. A la vista de todo ello, el informe es emitido finalmente por un comité técnico creado al efecto, en el plazo máximo de un mes contado desde la presentación de la solicitud.

${ }^{63}$ Esta norma reproduce las exigencias previstas en el artículo 1.4 del Real Decreto Legislativo de 1986 (de acuerdo con la redacción dada por la Ley 9/2006).

${ }^{64}$ Los conceptos de «administraciones públicas afectadas» y «público interesado» aparecen definidos en el artículo 3 de la ley. Para el primer concepto se sigue la definición que el artículo 9 de la Ley 9/ 2006 establece a efectos de la evaluación estratégica de impacto ambiental. En cuanto a la definición del segundo concepto, está tomada de la recogida en el artículo 1 bis del Real Decreto Legislativo de 1986 (redactado por la Ley 27/2006).

65 A diferencia del Real Decreto Legislativo de 1986, la Ley 11/2006 no señala expresamente que con la solicitud de autorización del proyecto deba acompañarse el estudio de impacto ambiental. No obs-
} 
repercusiones ambientales, pues la Ley 11/2006 condiciona el inicio de éste al cumplimiento previo de una serie de trámites en el procedimiento de autorización. Los trámites que se han de observar en el procedimiento de autorización en relación al estudio de impacto ambiental son los tres siguientes. Primero, información pública. El proyecto, juntamente con el estudio de impacto ambiental, deberá someterse a información pública, por un periodo no inferior a treinta días y en una fase del procedimiento de autorización en la cual estén todavía abiertas todas las opciones relativas a la determinación del contenido del proyecto sujeto a autorización ${ }^{66}$. A fin de que la participación pública pueda tener un sentido real y efectivo, la Ley 11/2006 dispone que, durante el trámite, el órgano sustantivo deberá informar al público sobre los diferentes aspectos señalados en el $28.2^{67}$. No hace ninguna mención la ley, por el contrario, al plazo máximo que tenga el promotor del proyecto para someter el estudio de impacto ambiental al trámite de información pública, y cuyo incumplimiento haya de determinar entonces el archivo del expediente y la obligación de iniciar nuevamente el trámite de evaluación de impacto ambiental. Se incumple de este modo, pues, lo señalado en el artículo 2.4 del Real Decreto Legislativo de 1986, donde se establece que corresponde a las comunidades autónomas la fijación del plazo señalado. Segundo, participación de las administraciones afectadas y del público interesado. Simultáneamente al trámite de información pública el órgano sustantivo consultará con las administraciones que ya expresaron su opinión sobre el alcance del estudio de impacto ambiental, informando a éstas y, a la vez, al público interesado de su derecho a participar en el procedimiento de autorización formulando las alegaciones y observaciones que consideren oportunas ${ }^{68}$. A tal efecto, deberá ponerse en su conocimiento la autoridad ante la cual hayan de hacer efectiva la participación y el plazo para ello, que en ningún caso podrá ser inferior a treinta días. Para tal participación, asimismo, la Ley 11/2006 prescribe que el órgano sustantivo deberá poner a disposición de las administraciones afectadas y del público interesado la distinta información que se

tante, es fácil suponer que ello deberá ser así, pues de otro modo resultaría difícil dar cumplimiento a los diferentes trámites que la ley autonómica prescribe para el procedimiento de autorización.

${ }^{66}$ Para el supuesto que en el proyecto de autorización no estuviera previsto el trámite de información pública, el artículo 28.5 de la ley autonómica dispone que el órgano ambiental someterá directamente el proyecto y el estudio de impacto ambiental a este trámite y solicitará los informes que, en su caso, considere oportunos.

${ }^{67}$ La enumeración de este artículo reproduce fielmente lo señalado en el artículo 3.2 del Real Decreto Legislativo de 1986 (según redacción dada por la Ley 27/20006), que a su vez reproduce lo establecido en el artículo 6.2 de la Directiva de 1985 (según redacción dada por la directiva 2003/35/CE).

${ }^{68}$ Se trata de autoridades y público nacional. Las consultas transfronterizas aparecen previstas en el artículo 30, para el supuesto de que el proyecto sometido a la autorización de la Comunidad Autóno$\mathrm{ma}$, los Consejos Insulares o los Entes Locales pudiera generar impactos negativos sobre el medio ambiente de otro Estado (distinto de España) miembro de la Unión Europea. En estos casos la Ley 11/ 2006 dispone que corresponde al Gobierno de las Islas Baleares suspender el procedimiento de aprobación del proyecto y comunicarlo al órgano competente de la Administración General del Estado responsable, de acuerdo con el Real Decreto Legislativo de 1986, de dar cauce a las consultas transfronterizas. 
señala en los apartados 3 y 4 del artículo $28^{69}$. Y tercero, informes. El artículo 28 de la Ley 11/2006 establece, por último, que el proyecto y el estudio de impacto ambiental se someterán al trámite de informes que en su caso prescriba la normativa específica reguladora del procedimiento de autorización.

Cumplidos todos los anteriores trámites, llega sí el momento de poder iniciar el procedimiento (estricto sensu) de evaluación de impacto ambiental, que se hará efectivo mediante solicitud del promotor cursada a través del órgano sustantivo. La imposibilidad de haberlo hecho hasta ahora deriva de la documentación que la Ley (art. 25) exige como acompañamiento de la solicitud de inicio $^{70}$.

En relación al inicio del procedimiento de evaluación hay dos cuestiones que merecen especial atención. Por una parte, cabe observar que entre la distinta documentación que ha de acompañar a la solicitud de inicio nada se dice respecto al resultado del trámite de participación de las administraciones públicas afectadas y del público interesado, a diferencia de los que sucede con la información pública. Por otro lado, tampoco señala nada la ley respecto del plazo máximo de que dispone el órgano sustantivo para remitir el expediente al órgano ambiental, incumpliendo de este modo lo prescrito en el artículo 4.1 del Real Decreto Legislativo de 1986, pues éste atribuye a las comunidades autónomas la fijación del plazo referido. Esta última circunstancia responde, sin duda, a la particular configuración que la ley autonómica hace de los dos procedimientos en juego, el de autorización del proyecto y el de evaluación de sus repercusiones ambientales. A diferencia de lo que sucede en el Real Decreto Legislativo, del que se desprende una clara voluntad de integración del segundo en el primero, la Ley 11/2006 parece mantener una mayor independencia entre ambos procedimientos. Ello lo demuestra el hecho de que el inicio del procedimiento de evaluación se deje, al igual que sucede con el de autorización, a la iniciativa del promotor. Sucede, pues, lo contrario a la idea que inspira el Real Decreto Legislativo de 1986, en el cual, una vez iniciado por el promotor el procedimiento de autorización, la conducción del procedimiento de evaluación corresponde al órgano sustantivo. Parece con ello, en fin, que la ley autonómica pretendiera dotar de mayor sustantividad propia al procedimiento de evaluación, eludiendo cualquier

\footnotetext{
${ }^{69}$ La Ley 11/2006 se ajusta aquí a lo dispuesto en los apartados 3 y 4 del Real Decreto Legislativo de 1986 (en la redacción de la Ley 27/2006), que a su vez sigue lo recogido en el artículo 6.3 de la Directiva de 1985 (en la versión dada por la Directiva 2003/35/CE).

${ }^{70}$ Los documentos exigidos son los siguientes: i) copia completa del proyecto; ii) estudio de impacto ambiental; iii) certificado de la información pública del proyecto y del estudio de impacto ambiental, así cono copia de las alegaciones formuladas y un informe valorativo de las mismas que puedan ser relevantes a efectos ambientales; iv) informes emitidos obrantes en el expediente que sena relevantes; v) resguardo acreditativo del pago de la tasa correspondiente (relacionado con este último requisitos debe verse la disposición adicional tercera de la Ley, que regula la tasa de evaluación de impacto ambiental, informe ambiental y evaluación ambiental estratégica, modificando lo dispuesto en el artículo 124 de la Ley 11/1998, de 14 de diciembre, sobre régimen específico de tasas de la Comunidad Autónoma de las Islas Baleares.
} 
LA EVALUACIÓN DE IMPACTO AMBIENTAL EN LAS ISLAS BALEARES: LA NORMATIVA...

previsión que pudiera dar a entender una subordinación respecto del procedimiento de autorización. Esta circunstancia, que en si sola se podría valorar como positiva, no puede hacernos olvidar, sin embargo, el carácter instrumental que la evaluación ambiental tiene en relación al procedimiento de autorización. Y, además, los mayores problemas que pueden suscitarse en la práctica, por la mayor dificultad de acompasar los ritmos de ambos procedimientos.

Superada la fase de inicio se pone en marcha la tramitación, que se sigue con la solicitud de los informes que resultaran preceptivos o pudieran estimarse convenientes para la resolución. A partir de aquí, un comité técnico del órgano ambiental elaborará una propuesta de resolución, que posteriormente se elevará al órgano ambiental para la formulación de la declaración de impacto ambiental. Dicha declaración, que debe emitirse en el plazo de tres meses desde la presentación de la solicitud, se pronunciará sobre la conveniencia o no de realizar el proyecto y, en caso afirmativo, sobre las medidas protectoras, correctoras o compensatorias que correspondiera adoptar, así como sobre las prescripciones oportunas al efecto del seguimiento del programa de vigilancia ambiental.

La declaración de impacto ambiental se comunicará al órgano sustantivo para la ulterior decisión de éste sobre la autorización del proyecto. No obstante, la Ley 11/2006 impone también al órgano ambiental que de a la declaración impacto ambiental general conocimiento mediante la publicación en el Boletín Oficial de las Islas Baleares, que comprenderá los diferentes extremos señalados en el artículo $37^{71}$. En caso de existir discrepancias entre el órgano ambiental y el sustantivo sobre la autorización del proyecto se abrirá un periodo de consultas entre ambos, a fin de llegar a un acuerdo en el plazo máximo de un mes. De persistir la divergencia, el artículo 36 de la ley atribuye la competencia para resolver sobre el proyecto al Consejo de Gobierno de la Comunidad Autónoma, siempre que se trate de proyectos que hayan de ser autorizados por órganos de ésta. En otro caso, se formará una comisión paritaria integrada por representantes de la Comunidad Autónoma y de la Administración sustantiva, correspondiendo a ésta última el voto de calidad en caso de empate.

Por último, una vez adoptada la decisión, sólo queda dar publicidad a la misma, lo que corresponde al órgano sustantivo, que asimismo deberá poner a disposición del público toda la diversa información que exige el artículo $38^{72}$.

\footnotetext{
${ }_{11}$ El apartado 2 del artículo 37 dispone que la publicación comprenderá, como mínimo, los siguientes aspectos: «a) Una descripción general del proyecto. b) Un resumen del estudio de impacto ambiental. c) El resultado de las consultas y de la información pública sobre el impacto ambiental del proyecto. d) El acuerdo del órgano ambiental sobre la declaración de impacto ambiental. e) El acuerdo de resolución de discrepancias, en su caso». Según el apartado 1 del mismo artículo, la publicación se efectuará en el plazo máximo de un mes a contar desde su adopción.

${ }^{72}$ Las exigencias de este artículo coinciden plenamente con las consignadas en el artículo 4 bis del Real Decreto Legislativo de 1986 (introducido por la Ley 9/2006).
} 
Todos los trámites expuestos hasta aquí afectan al que podría denominarse procedimiento tipo o estándar, aplicable a los proyectos del anexo $\mathrm{I}^{73}$. Igual procedimiento se aplica también a los proyectos del anexo II y a aquellos otros que, no incluidos en el anexo I, afecten a espacios de la Red Ecológica Europea Natura $2000^{74}$, si bien que entonces la Ley 11/2006 incorpora algunos trámites adicionales, anteriores a la fase de consultas previas, destinados a resolver sobre la necesidad o no de someter el concreto proyecto a evaluación de impacto ambiental. A este efecto, el promotor del proyecto deberá comunicar el órgano ambiental, por conducto del órgano sustantivo, su propósito de llevarlo a efecto, acompañando a la comunicación un documento ambiental que incluya los contenidos señalados en el artículo $41.2^{75}$. Este documento, unido al escrito de comunicación, se pondrá a disposición de las administraciones, personas e instituciones afectadas, al objeto de establecer consultas con ellas, concediéndoles un plazo de quince días para que expresen su parecer. A partir de aquí, un comité técnico del órgano ambiental elaborará una propuesta razonada que elevará a éste para que decida, en el plazo de dos meses, sobre la necesidad o no de someter el proyecto a evaluación de impacto ambiental ${ }^{76}$. Para tomar tal decisión deberán observarse, en todo caso, los criterios relacionados en el artículo $44^{77}$. Finalmente, la decisión será publicada por el órgano ambiental en el Boletín Oficial de las Islas Baleares. Contra la misma, que agota la vía administrativa, podrá interponerse recurso administrativo de reposición o, directamente, recurso contencioso-administrativo ${ }^{78}$.

D) Más allá de los tres aspectos esenciales que se ha expuesto hasta ahora, la Ley 11/2006 incluye en el régimen de la evaluación de proyectos un cuarto aspecto que conviene también destacar, más aún cuando estaba completamente huérfano de regulación en el Decreto 4/1986: se trata de la denominada «dis-

\footnotetext{
73 Teóricamente el mismo procedimiento debería aplicarse a los proyectos que menciona el artículo 10.3 de la Ley, es decir, aquellos no incluidos en los anexos I y II pero que deben someterse a evaluación de impacto ambiental por disposición expresa de la normativa sectorial o de un plan territorial o medioambiental. Curiosamente, no obstante, la Ley no hace ninguna mención a ellos a los largo de los diferentes artículos destinados a regular el procedimiento, limitando siempre sus alusiones a los proyectos del anexo I.

74 Así lo dispone expresamente el artículo 46 de la ley.

75 Las exigencias de este artículo, referentes en esencia a las características del proyecto, las alternativas estudiadas, los impactos potenciales sobre el medio ambiente y las medidas preventivas, correctoras o compensatorias, se adecuan perfectamente a lo prescrito en el artículo 1.5 del Real Decreto Legislativo de 1986 (según redacción de la Ley 9/2006), e incluso van más allá.

${ }^{76}$ La falta de resolución y notificación en el plazo expresado supondrá, según dispone el artículo 44.3, la sujeción del proyecto a evaluación de impacto ambiental.

77 Son los mismos criterios que se recogen en el anexo III del Real Decreto Legislativo de 1986 (según la redacción dada por la Ley 6/2001)

${ }^{78}$ A efectos de articular el recurso hubiera sido preceptivo que la Ley 11/2006 previera dar cuenta al promotor del contenido de las consultas efectuadas, máxime cuando tal exigencia viene impuesta por el artículo 1.7 del Real Decreto Legislativo de 1986. En este sentido, pues, la norma autonómica no se ajusta a lo prescrito por la legislación básica estatal.
} 
ciplina ambiental». Bajo este título, la ley autonómica dedica extensa atención a un conjunto heterogéneo de actuaciones que tienen, como elemento común, la finalidad de asegurar la observancia de las prescripciones impuesta en materia de evaluación medioambiental y, en su caso, los resultados derivados de la declaración de impacto ambiental. En concreto, se recogen en el título de disciplina ambiental los siguientes supuestos, algunos de los cuales constituyen aportaciones propias de la ley autonómica: i) fianzas y seguros de responsabilidad; ii) vigilancia y seguimiento; iii) caducidad o modificación de la declaración de impacto; iv) infracciones y sanciones; v) medidas cautelares; vi) restitución de la realidad física alterada e indemnización de daños y perjuicios; g) ejecución forzosa; y vii) prestación ambiental sustitutoria. Asimismo, también debe entenderse comprendida dentro de la disciplina ambiental la revisión de oficio de los actos administrativos de autorización que se hubieran adoptado sin la preceptiva evaluación de impacto ambiental.

Todo este complejo de medidas parte, en todo caso, del principio básico que atribuye a los órganos sustantivos el ejercicio de las competencias de disciplina ambiental. No obstante, se reconoce al órgano ambiental la facultad de recabar información del órgano sustantivo, de hacer las comprobaciones que considere oportunas y, en su caso, de formular requerimientos ${ }^{79}$.

\section{La evaluación de planes y programas}

A) La inclusión en la Ley 11/2006 de esta segunda modalidad de evaluación de impacto ambiental pone en evidencia la rápida reacción dada por la Comunidad Autónoma de las Islas Baleares a las innovaciones introducidas por la Ley estatal 9/2006. De hecho, la Ley 11/2006 constituye una de las primeras regulaciones de la evaluación estratégica aparecidas en el estado español ${ }^{80}$. La ley balear, como no cabía esperar otra cosa, sigue la sistemática de la normativa estatal, ocupándose, por una parte, de definir el ámbito de aplicación de la evaluación medioambiental y, por otra, de regular su procedimiento.

B) En lo que se refiere al ámbito de aplicación de la evaluación, la Ley $11 / 2006$ recoge las tres categorías de la ley estatal. La primera, formada por los planes y programas que necesariamente deberán someterse a evaluación de impacto ambiental, cuya enumeración se recoge en el anexo III de la ley ${ }^{81}$.

\footnotetext{
79 Incluso en algunos supuestos, como en el caso del régimen sancionador, la ley prevé la posibilidad de que el órgano ambiental pueda sustituir al órgano sustantivo en el ejercicio de las competencias para la tramitación y resolución de los correspondientes expedientes.

${ }^{80}$ Anteriores a la ley balear se pueden citar las leyes de las comunidades autónomas de Madrid (ésta incluso anterior a la legislación básica estatal) y Aragón, ambas reseñadas en la nota 7

${ }^{81}$ Este anexo reproduce en esencia lo dicho en el artículo 3.2 de la Ley 9/2006. No obstante, cabe apreciar una diferencia de matiz significativa. El anexo III de Ley 11/2006 recoge en su enumeración «los planes que supongan la ordenación del territorio urbano o rural o utilización del suelo», pero lo hace
} 
La segunda, la que integran los planes y programas que no necesariamente se han de someter a evaluación medioambiental, sino sólo cuando así lo determine el órgano ambiental; son los señalados en el artículo $17^{82}$. No obstante, la ley prevé, en el artículo 97.2, que mediante reglamento se fije si la sujeción a evaluación medioambiental de estos planes y programas haya de realizarse caso por caso, mediante lista de categorías o, incluso, combinando ambos métodos. La tercera, finalmente, formada por los planes y programas excluidos de la aplicación de la ley, que se relacionan en el artículo 18 y en la disposición transitoria sexta ${ }^{83}$.

C) En cuanto al procedimiento de la evaluación estratégica, la Ley 11/2006 lo estructura de acuerdo con las cinco etapas o fases ya examinadas en la Ley 9/2006. La primera es la del informe de sostenibilidad ambiental, que ha de formar parte integrante de la documentación del plan o programa. El contenido de este informe aparece detallado en el artículo 87 de la Ley, en términos coincidentes con los que establece el anexo I de la Ley estatal 9/2006. Corresponde al órgano ambiental determinar el alcance y nivel de detalle de la información que ha de ofrecer el informe sobre los distintos extremos que lo integran. Para ello, el órgano ambiental mantendrá consultas con las administraciones públicas afectadas y el público interesado, de acuerdo con las modalidades definidas por el propio órgano ambiental. Finalmente, la Ley 9/2006 dispone la obligación de dar publicidad al contenido de las actuaciones llevadas a cabo para determinar el alcance y extensión del informe de sostenibilidad ambiental; sin embargo, esta previsión no aparece recogida por la ley autonómica, produciéndose en este sentido una clara omisión de un requisitos esencial de la normativa estatal. La segunda fase es la de consulta, a cuyo efecto el proyecto de plan o programa, junto con el informe de sostenibilidad ambiental, se debe poner a disposición del público y someterse a la consideración de los órganos y entidades que establezca la legislación sectorial, de las administraciones públicas afectadas, del público interesado y del órgano ambiental ${ }^{84}$. El plazo para formular observaciones será, como

\footnotetext{
de forma separada al resto de planes o programas «que establezcan el marco para la futura autorización de proyectos sometidos a evaluación de impacto ambiental». Quiere decir ello, por tanto, que este último condicionante trascrito no rige para los planes o programas de ordenación o utilización del suelo, de tal manera que los mismos quedan siempre sometidos a evaluación estratégica. De este modo, en definitiva, puede decirse que, en relación a tales planes, la Ley autonómica establece una ámbito de aplicación de la evaluación medioambiental superior al fijado por la legislación estatal.

${ }^{82}$ Coincide esta enumeración con la del artículo 1.4 de la Ley 9/2006. Se trata, pues, de los planes y programas distintos de los enumerados en el anexo III que establezcan el marco para la autorización futura de proyectos y, también, de aquellos que, aunque incluidos entre los del citado anexo, constituyan modificaciones menores de estos o establezcan el uso de reducidas zonas de ámbito territorial. La Ley 11/2006 define los conceptos de «zonas de reducido ámbito territorial» y de «modificaciones menores» en los mismos términos que la ley estatal.

${ }^{83}$ La relación se corresponde perfectamente con lo previsto en la Ley 9/2006, que reproduce a la vez las previsiones de la Directiva de 2001. De este modo, valga lo dicho en la nota 63.

${ }^{84}$ El régimen de las consultas transfronterizas aparece regulado en el artículo 90 de la ley, que prevé la suspensión del procedimiento de aprobación del plan o programa por parte del Gobierno de las Islas
} 
LA EVALUACIÓN DE IMPACTO AMBIENTAL EN LAS ISLAS BALEARES: LA NORMATIVA...

mínimo, de cuarenta y cinco días. La tercera fase es la de la memoria ambiental, que debe elaborar el órgano promotor en colaboración con el órgano ambiental, y que tiene como finalidad valorar la integración de los aspectos ambientales en la propuesta de plan o programa. Los cometidos específicos de la memoria los detalla el artículo 91 de acuerdo con lo dispuesto en el artículo 12 de la Ley 9/2006. Una vez elaborada la memoria el órgano promotor la enviará al órgano ambiental, para que manifieste su conformidad o disconformidad con la misma (en el plazo de dos meses). Esta declaración del órgano ambiental, a su vez, se publicará en el Boletín Oficial de las Islas Baleares (en el plazo de un mes desde su adopción) para general conocimiento. La cuarta fase es la de toma de decisión, que compete al órgano promotor, debiendo tener siempre en cuenta el informe de sostenibilidad ambiental, las alegaciones formuladas en la fase de consulta (incluidas las consultas transfronterizas, en su caso), la memoria ambiental y el acuerdo del órgano ambiental sobre ésta. Si existiera discrepancia entre el órgano ambiental y el órgano sustantivo la ley manda que se resuelva del mismo modo que el establecido para la evaluación de proyectos. La última fase, la quinta, es la que se refiere a la publicidad de la decisión adoptada sobre el plan o proyecto. Al respecto, la Ley 11/2006 obliga al órgano promotor, una vez adoptada la decisión, a poner a disposición del órgano ambiental, de las administraciones públicas afectadas y del público (también en su caso de los estados consultados) la distinta documentación que enumera el artículo 92.3. Entre ésta no se exige, sin embargo, el resumen no técnico al que se refiere la Ley 9/ $2006^{85}$. Sí figura, por el contrario, la exigencia referida a las medidas adoptadas para el seguimiento de los efectos en el medio ambiente derivados de la aplicación del plan o programa, lo cual conecta con la obligación que al respecto se impone al promotor en el artículo 94, que contará siempre con la participación del órgano ambiental.

Sobre la base del esquema descrito la Ley 11/2006 diseña las particularidades del procedimiento de evaluación de los planes y programas en principio no sometidos preceptivamente a ella; especialidades, en todo caso, que afectan únicamente al momento de adoptar la decisión sobre la necesidad o no de someter la propuesta de plan o programa a evaluación medioambiental, pues en lo demás el procedimiento es exactamente el mismo que se ha visto en el párrafo anterior. La ley dispone, en este sentido, que el órgano promotor remitirá a las administraciones afectadas por el plan o programa una memoria-análisis sobre los posibles efectos significativos sobre el medio ambiente de dicho plan o programa, así como una copia de la documentación sobre la orientación inicial o preliminar del plan o programa y sus objetivos concretos, indicando los factores o elementos ambientales afectados por él.

Baleares y la posterior comunicación al órgano competente de la Administración General del Estado, acompañada de la misma documentación que exige el artículo 11 de la Ley 9/2006, para que sea éste el que inicie el trámite de consultas en los términos establecidos en el citado artículo 11.

${ }^{85}$ Salvo en este aspecto señalado, los requisitos del artículo 92.3 de la ley autonómica coinciden con los prescritos por el artículo 14 de la Ley 9/2006. 
A la vista de la documentación remitida las administraciones públicas afectadas podrán formular las observaciones que consideren oportunas, disponiendo para ello de un plazo máximo de un mes ${ }^{86}$. Formuladas las alegaciones o, en otro caso, transcurrido el plazo señalado, el órgano promotor remitirá al órgano ambiental toda la documentación recabada, acompañada de las propias conclusiones sobre la necesidad o no de sujetar la propuesta de plan o programa a evaluación ambiental estratégica. El órgano ambiental deberá pronunciarse en el plazo máximo de dos meses contados desde la recepción de la documentación. Si no lo hiciera así, se entenderá entonces la necesidad de someter el plan o programa a evaluación ambiental. En cualquier caso, la decisión del órgano ambiental habrá de adoptarse de acuerdo con los criterios establecidos en el artículo 97, que se adecuan a los que establece el anexo II de la Ley 9/2006.

D) Finalmente, al margen de las dos cuestiones tratadas en los apartados anteriores, mencionar que la ley dedica también su atención a la regulación de la disciplina ambiental en materia de evaluación estratégica, aunque con mucha menor extensión que en el caso de la evaluación de proyectos. En concreto, bajo este título se recogen tres supuestos diferenciados: la ejecución y el seguimiento ambiental del plan o programa, la revisión de oficio de los planes o programas aprobados sin haber seguido el procedimiento establecido y el régimen de infracciones y sanciones, aplicable sólo a los planes y programas de ejecución privada que comprendan la realización de proyectos no sometidos a evaluación de impacto ambiental. La ley mantiene en todos estos casos el principio básico de atribución de la competencia sobre disciplina ambiental al órgano promotor, sin perjuicio de la participación en su caso del órgano ambiental.

\section{Especial referencia al régimen transitorio de la Ley $11 / 2006$}

Atención especial e individualizada merece la exposición del régimen transitorio que establece la Ley 11/2006 en las disposiciones transitorias segunda, tercera y cuarta, pues tal vez es aquí donde se encuentra uno de los motivos de mayor crítica que pueda hacerse a la ley autonómica.

La disposición transitoria segunda es la que define el régimen de intertemporalidad aplicable a los procedimientos de evaluación de proyectos iniciados con anterioridad a la entrada en vigor de la Ley 11/2006. En concreto, dispone que los procedimientos de evaluación iniciados de acuerdo con lo establecido en el Decreto 4/1986 continuaran su tramitación conforme con éste, no siéndoles aplicables en consecuencia las determinaciones de la ley. Así pues, no obstante la derogación del mencionado Decreto ${ }^{87}$, en la prácti-

\footnotetext{
${ }^{86} \mathrm{El}$ artículo 97.2 establece que una vez transcurrido el plazo sin que se hayan formulado y notificado observaciones podrá entenderse que el plan o programa no afecta al factor o elemento tutelado por la concreta administración consultada, y en consecuencia podrá continuarse la tramitación.

87 Véase nota 48.
} 
LA EVALUACIÓN DE IMPACTO AMBIENTAL EN LAS ISLAS BALEARES: LA NORMATIVA...

ca éste está llamado a pervivir aún durante algún tiempo, lo que a la postre supone la persistencia en la inobservancia de las exigencias impuestas por la normativa comunitaria y estatal en relación a la evaluación de proyectos. Por otra parte, obsérvese que la disposición transitoria no dice nada sobre el régimen aplicable a los procedimientos de autorización iniciados antes de la entrada en vigor de la ley y referidos a proyectos no sometidos a evaluación conforme al Decreto 4/1986 pero sí de acuerdo con la nueva legislación. Ante esta situación sólo caben dos alternativas. La primera, considerar que tales procedimientos se rigen por el Decreto de 1986, lo que comportará en la práctica su exclusión del procedimiento de evaluación. La segunda, entender que dichos procedimientos quedan en todo caso sujetos a evaluación conforme a las exigencias de la legislación comunitaria y básica estatal. En el primer caso, se ahondará aún un poco más en el reiterado incumplimiento del Derecho comunitario y estatal; en el segundo, por su parte, se pondrá en evidencia el desacierto y lo absurdo de la solución adoptada en la disposición transitoria para los procedimientos sometidos al Decreto 4/1986.

El régimen transitorio de la evaluación estratégica se establece en las disposiciones tercera y cuarta. La primera de ellas reproduce las previsiones ya conocidas de la Ley 9/2006 (disposición transitoria primera), que se articulan en torno a las fechas 21 de julio de 2004 y 21 de julio de 2006, y en atención a que el primer acto preparatorio formal del plan o programa sea anterior o posterior a la primera de las fechas señaladas. Así pues, el procedimiento de evaluación estratégica que regula la Ley 11/2006 resultará aplicable, de un lado, a los planes y programas cuyo primer acto preparatorio formal sea posterior al 21 de julio de 2004, y, de otro, a los planes o programas que, aún siendo el primer acto preparatorio formal anterior al 21 de julio de 2004, se hayan de aprobar definitivamente después del 21 de julio de 2006. Para este último supuesto, sin embargo, la ley prevé que el órgano ambiental pueda excluir la evaluación medioambiental cuando se justifique, caso por caso y de forma motivada, que la misma resulta inviable. Cabe señalar, de todos modos, que es ésta una excepción igualmente prevista en la Ley 9/2006, de tal manera que no puede decirse que exista con ello incumplimiento de la normativa básica. Aún que sí debe advertirse que de la conexión de la disposición transitoria primera y el artículo 5 de la Ley 9/2006 resulta que la competencia para acordar la exclusión señalada corresponde al órgano sustantivo, y no al órgano ambiental.

Sin perjuicio de lo anterior, el verdadero punto de conflicto con la Directiva de 2001 y la Ley 9/2006 se encuentra en la disposición transitoria cuarta. Vale la pena transcribir aquí su texto: «Los planes y programas urbanísticos municipales que quedan sujetos a evaluación ambiental estratégica por la extensión a todo el planeamiento urbanístico prevista en esta ley, en los que el primer acto preparatorio formal sea posterior a 21 de julio de 2004, y en el momento de la entrada en vigor de la Ley 9/2006 (...) haya finalizado el periodo de información pública en el procedimiento sustantivo, la obligación 
de evaluación ambiental durante la tramitación y antes de la aprobación se tramitará de conformidad a las previsiones del Decreto 4/1986, de 23 de enero». Sin duda la norma es clara en su propósito: se trata ni más ni menos que de excluir de la regla general de sumisión a evaluación estratégica una determinada categoría específica de planes, seguramente los de mayor relevancia en las Islas Baleares, los urbanísticos.

De entrada, no se entiende de ningún modo la razón por la cual esta categoría concreta de planes, y no otra, haya de excepcionarse de la regla general contenida en la disposición transitoria tercera. Podrá haber quien alegue que la razón se encuentra en que se trata de planes ya sometidos a evaluación conforme al Decreto 4/1986. Sin embargo, el argumento no es admisible, porque tampoco es admisible que los objetivos que persigue la evaluación estratégica se puedan satisfacer correctamente con las determinaciones del Decreto 4/1986. Como ya se ha dicho en otro momento, la regulación contenida en esta norma reglamentaria dista mucho, en cuanto a ámbito de aplicación, contenido y procedimiento de evaluación, de las exigencias impuestas por la Directiva de 2001 y la Ley estatal de 2006 y, siguiendo a éstas, por la propia Ley autonómica 11/2006.

Al margen de razones, se trata asimismo de una excepción directamente proscrita por el Derecho comunitario. La Directiva 2001/42/CE no admite excepciones a la regla impuesta (la coincidente con la disposición transitoria tercera), y tampoco las necesita, supuesta la diligencia de los estados miembros en la incorporación al ordenamiento interno de las exigencias comunitarias. Y, si bien es cierto que tal diligencia con frecuencia no es regla de conducta general, ello de ningún modo puede servir para motivar o justificar supuestos de exclusión transitoria de las prescripciones comunitarias. La Ley 11/2006 olvida, en este sentido, la reciente condena — referida más arriba- del Tribunal de Justicia de las Comunidades Europeas al Estado español por incumplimiento de la Directiva de $1985^{88}$, en su versión de 1997, que tiene precisamente como uno de sus motivos la aplicación del régimen transitorio. El artículo 3 de la Directiva 1997/11/CE establecía como fecha límite par su transposición el día 14 de marzo de 1999, disponiendo la aplicación de la versión inicial de la Directiva 1985/337/CEE a las solicitudes presentadas con anterioridad a la fecha indicada. Suponía ello, por tanto, que la nueva versión de la Directiva se había de aplicar a todas las solicitudes de autorización presentadas con posterioridad al día 14 de marzo de 1999. Sin embargo, cuando la mencionada Directiva de 1997 fue incorporada tardíamente al ordenamiento interno mediante el Real Decreto-ley 9/2000, éste dispuso, y lo mismo hizo luego la Ley 6/2001, que la norma estatal no fuera aplicable a las solicitudes de autorización presentadas antes de su entrada en vigor. En definitiva, pues, lo que se estaba haciendo era excluir la aplicación de la Directiva, en contra de lo prescrito por ésta, a las solicitudes de autorización

\footnotetext{
88 Véase nota 61.
} 
presentadas después del día 14 de marzo de 1999 y antes de la fecha de entrada en vigor de las respetivas normas estatales. Se estaba incumpliendo, en fin, lo mandado por la Directiva. La condena no admite oposición ${ }^{89}$.

El planteamiento claro que ha venido manteniendo la jurisprudencia comunitaria, que se expresa en la sentencia señalada, hace difícilmente explicable una regla del tipo de la contenida en la disposición transitoria cuarta de la Ley 11/2006. Pero, más aún, es inexplicable que la fecha tomada como referencia sea la de entrada en vigor de la Ley estatal 9/2006, cuando resulta que ésta, por una parte, no prevé -ni podía prever- una excepción como la autonómica, $\mathrm{y}$, por otra parte, su entrada en vigor se produce también una vez expirado el plazo de transposición de la Directiva 2001/42/CE.

\section{Reflexión final}

La valoración en su conjunto de la Ley 11/2006 ha de ofrecer, sin duda, un resultado positivo. Con ella se cumple la labor pendiente en la Comunidad Autónoma de las Islas Baleares de establecer una normativa adecuada en lo esencial al marco definido por la legislación comunitaria y estatal. Desde que el Decreto 4/1986 quedara pronto superado por el contenido del amplio bloque de normativa comunitaria y estatal sobrevenida se había puesto de manifiesto la necesidad de introducir modificaciones estructurales, de base, en el régimen autonómico de la evaluación de impacto ambiental. Estos cambios han tardado en exceso en llegar, y durante mucho tiempo las Islas Baleares se han mantenido en una situación que difícilmente era sostenible. La Ley 11/2006 ha querido poner punto y final a esta situación, a la vez que ha venido a completar el cuadro normativo de los estudios de impacto ambiental con la regulación de la nueva modalidad de la evaluación estratégica. Podríamos decir, en definitiva, que el esfuerzo más importante ya se ha realizado, que el edificio autonómico de las evaluaciones de impacto ambiental se ha reconstruido con unos adecuados cimientos. No obstante, quedan algunos detalles de la obra que deben ser mejorados, lo que desde luego debería obligar en el futuro a las oportunas correcciones.

\footnotetext{
89 Conforme con ella, la disposición derogatoria de la Ley 9/2006 deroga la disposición transitoria única («Procedimiento en curso») de la Ley 6/2001.
} 